\title{
Loss of syd-1 from R7 Neurons Disrupts Two Distinct Phases of Presynaptic Development
}

\author{
Scott Holbrook, Jennifer K. Finley, Eric L. Lyons, and Tory G. Herman \\ Institute of Molecular Biology, University of Oregon, Eugene, Oregon 97403
}

Genetic analyses in both worm and fly have identified the RhoGAP-like protein Syd-1 as a key positive regulator of presynaptic assembly. In worm, loss of syd-1 can be fully rescued by overexpressing wild-type Liprin- $\alpha$, suggesting that the primary function of Syd-1 in this process is to recruit Liprin- $\alpha$. We show that loss of syd-1 from Drosophila R7 photoreceptors causes two morphological defects that occur at distinct developmental time points. First, syd-1 mutant R7 axons often fail to form terminal boutons in their normal M6 target layer. Later, those mutant axons that do contact M6 often project thin extensions beyond it. We find that the earlier defect coincides with a failure to localize synaptic vesicles, suggesting that it reflects a failure in presynaptic assembly. We then analyze the relationship between syd-1 and Liprin- $\boldsymbol{\alpha}$ in R7s. We find that loss of Liprin- $\boldsymbol{\alpha}$ causes a stronger early R7 defect and provide a possible explanation for this disparity: we show that Liprin- $\boldsymbol{\alpha}$ promotes Kinesin-3/Unc-104/Imac-mediated axon transport independently of Syd-1 and that Kinesin3/Unc-104/Imac is required for normal R7 bouton formation. Unlike loss of syd-1, loss of Liprin- $\boldsymbol{\alpha}$ does not cause late R7 extensions. We show that overexpressing Liprin- $\boldsymbol{\alpha}$ partly rescues the early but not the late syd-1 mutant R7 defect. We therefore conclude that the two defects are caused by distinct molecular mechanisms. We find that Trio overexpression rescues both $s y d-1$ defects and that trio and syd-1 have similar loss- and gain-of-function phenotypes, suggesting that the primary function of Syd-1 in R7s may be to promote Trio activity.

\section{Introduction}

Synapse development is initiated by adhesion molecules that recruit presynaptic and postsynaptic components to the site of contact. The RhoGAP-like protein Syd-1 is among the earliest such components to be recruited presynaptically, and its loss disrupts the localization of multiple presynaptic proteins, including the scaffold Liprin- $\alpha$ (Hallam et al., 2002; Dai et al., 2006; Patel et al., 2006; Owald et al., 2010, 2012). In worm, loss of syd-1 is rescued by overexpressing Liprin- $\alpha$, suggesting that the primary function of Syd-1 may be to recruit or potentiate Liprin- $\alpha$ activity (Dai et al., 2006; Patel et al., 2006; Patel and Shen, 2009).

The R7 photoreceptor neurons in the Drosophila eye provide a genetically tractable system in which to study presynaptic development. Wild-type R7s extend their axons to the medulla, in which they eventually form presynaptic boutons in layer M6 (Ting et al., 2005). The best-studied synapses are those between motor neurons and muscle. Less is known about how neurons such as R7s form synapses onto other neurons. At both fly neuromuscular junction (NMJ) and in R7s, presynaptic develop-

Received March 14, 2012; revised Sept. 17, 2012; accepted 0ct. 5, 2012.

Author contributions: S.H., J.K.F., and T.G.H. designed research;S.H., J.K.F., E.L.L., and T.G.H. performed research; S.H., J.K.F., and T.G.H. analyzed data; T.G.H. wrote the paper.

This work was supported by institutional National Institutes of Health National Research Service Award Training Grant 5-T32-HD07348 (S.H.), a Burroughs-Wellcome Career Development Award (T.G.H.), and National Institutes of Health Grant R01 EY019694 (T.G.H.). We are deeply grateful to William Saxton, Angeline Lim, and other members of the Saxton laboratory for allowing us to use their expertise and laboratory facilities to perform the axon transport experiments. We also thank the Saxton laboratory as well as Jessica Treisman, Tom Schwarz, and the Bloomington Drosophila Stock Center for fly stocks.

Correspondence should be addressed to Dr. Tory G. Herman, Institute of Molecular Biology, University of Oregon, Eugene, 0R 97403. E-mail: herman@molbio.uoregon.edu.

DOI:10.1523/JNEUROSCI.1350-12.2012

Copyright $\odot 2012$ the authors $\quad 0270-6474 / 12 / 3218101-11 \$ 15.00 / 0$ ment requires the LAR receptor phosphatase (Clandinin et al., 2001; Maurel-Zaffran et al., 2001; Kaufmann et al., 2002), its binding partners Liprin- $\alpha$ (Kaufmann et al., 2002; Hofmeyer et al., 2006) and Liprin- $\beta$ (Astigarraga et al., 2010), and the guanine exchange factor (GEF) Trio (Astigarraga et al., 2010; Ball et al., 2010). However, the two systems use somewhat different molecular mechanisms (Hofmeyer and Treisman, 2009; Astigarraga et al., 2010), highlighting the importance of studying multiple synapse types. Disrupting members of the LAR/Liprin/Trio pathway in R7s causes two distinct phenotypes. (1) Loss of LAR or Liprin- $\alpha$ prevents R7 terminals from maintaining contact with M6, causing many axons instead to terminate in the M3-M5 layers (Clandinin et al., 2001; Maurel-Zaffran et al., 2001; Choe et al., 2006; Hofmeyer et al., 2006); late loss of the homophilic adhesion molecule N-cadherin (Ncad) also causes this phenotype (Lee et al., 2001; Nern et al., 2005; Ting et al., 2005). (2) In contrast, loss of Liprin- $\beta$ or Trio causes R7 terminals to extend beyond M6 (Astigarraga et al., 2010). Despite this dichotomy, overexpressing Trio in R7s rescues loss of LAR, Liprin- $\alpha$, or Liprin- $\beta$ (Maurel-Zaffran et al., 2001; Astigarraga et al., 2010), suggesting that Trio acts downstream of these genes and that the two R7 phenotypes might simply be different manifestations of the same underlying defect: a destabilized interaction with M6 (Astigarraga et al., 2010).

However, here we show that loss of syd-1 causes both R7 defects and that the two defects occur at separate developmental time points. The earlier failure to contact M6 correlates with a failure to localize synaptic vesicles (SVs) and can be partially rescued by Liprin- $\alpha$ overexpression, suggesting that part of the early role of Syd-1 is to promote presynaptic assembly by positively regulating Liprin- $\alpha$. The later projection of extensions is not ameliorated by either Liprin- $\alpha$ or Liprin- $\beta$ overexpression. 
However, Trio overexpression rescues both syd-1 mutant R7 defects, suggesting that the primary function of Syd-1 during both phases of R7 terminal development is to potentiate Trio activity.

\section{Materials and Methods}

Genetics. Individual homozygous R7s were generated and labeled using GMR-FLP and mosaic analysis with a repressible cell marker (MARCM) (Lee and Luo, 1999; Lee et al., 2001); homozygous cells expressed either UAS-Synaptotagmin (Syt)-GFP or UAS-mito-GFP under the control of actin (act)-Gal4 (flies containing the UAS constructs and act-Gal4 were obtained from the Bloomington Drosophila Stock Center). In each rescue experiment, the UAS construct to be tested was also present. Wholly homozygous retinas were generated using ey3.5-FLP (from Iris Salecker, Medical Research Council, London, UK) and techniques described in Stowers and Schwarz (1999). The animal in Figure 2, $F$ and $F^{\prime}$, is of genotype norpA $A^{36} / Y$; UAS-mito-GFP; PANR7-Gal4. Mito-GFP was similarly enriched within the R7 terminals of wild-type animals of genotype UAS-mito-GFP; PANR7-Gal4.

The $s y d-1^{w 46}$ allele was induced by ethylmethane sulfonate mutagenesis of a wild-type FRT82 chromosome and was mapped relative to DNA sequence polymorphisms between the FRT82 and rucuca chromosomes using meiotic recombination (Berger et al., 2001). The syd-1 ${ }^{C D}$ allele was generated by FLP-induced recombination between the FRTcontaining piggyBac insertions $P B a c\{W H\}$ ferrochelatase $e^{f 02660}$ and PBac $\left\{\right.$ WH\}RhoGAP100F $F^{f 04641}$ (Parks et al., 2004). The following mutations were also used: Liprin- $\alpha^{\text {oos }}$ (Hofmeyer et al., 2006), Liprin- $\alpha^{R 60}$ (Kaufmann et al., 2002), trio $^{1}$ and trio $^{3}$ (Newsome et al., 2000), $L A R^{2127}$ (Maurel-Zaffran et al., 2001), imac ${ }^{170}$ (Pack-Chung et al., 2007), sev ${ }^{V 1}$ (Mullins and Rubin, 1991), and norpA ${ }^{36}$ (McKay et al., 1995; RiesgoEscovar et al., 1995; Pearn et al., 1996). All animals used were raised at $25^{\circ} \mathrm{C}$. All norpA and sev mutant animals analyzed were male; the developmental time course (see Fig. 5) and axon transport (see Fig. 4) analyses were performed with a mixture of males and females; all other experiments were performed with females.

Transgenes. The incomplete fly syd-1 cDNA clone LD28013, the only one available at the time, was obtained from the Drosophila Genomics Resource Center and subcloned into the pGEM vector. The predicted missing $5^{\prime}$ region was amplified in several pieces from larval RNA by RT-PCR and appended to the incomplete cDNA. We were unable to amplify the first exon as predicted at the time and therefore synthesized the corresponding DNA sequence to complete our construction. This prediction has subsequently turned out to be incorrect: the N-terminal amino acid sequence MTVQPAEMA, encoded by our syd-1 cDNA, is not found within any of the currently predicted Syd- 1 isoforms. The remainder of our syd-1 cDNA encodes the Syd-1 C isoform, whose N terminus, however, contains the amino acid sequence MCDSATTGCFLTRSSHR in place of our incorrect $\mathrm{N}$-terminal sequence. We removed the stop codon from our assembled syd-1 cDNA and subcloned it into a UAST vector containing a C-terminal FLAG tag. The final UAS-syd-1-FLAG construct was sequenced to ensure that it contained no mutations and, as shown in Figure 2, $E$ and $F$, does fully rescue the syd-1 mutant R7 defect.

In addition to the transgenes used in the GMR-FLP/MARCM experiments (mentioned above), we also used the following: UAS-trio (Bloomington Drosophila Stock Center), UAS-HA-Liprin- $\alpha$ (Hofmeyer et al., 2006), UAS-HA-Liprin- $\beta$ (Astigarraga et al., 2010), UAS-ANF-GFP (Rao et al., 2001), PANR7-Gal4 (Wernet et al., 2006), UAS-N-synaptobrevin-GFP (Zhang et al., 2002), D42-Gal4 (Yeh et al., 1995), and OK371-Gal4 (Mahr and Aberle, 2006).

Image acquisition and analysis: R7s. Brains were dissected, fixed, and stained as described previously (Miller et al., 2008). The localization of Syt-GFP and Mito-GFP in R7s was analyzed in adults $\leq 12 \mathrm{~h}$ after eclosion; each marker is more diffusely distributed in R7 axons of adults that are older than $1 \mathrm{~d}$ old (data not shown). We used the following antibodies: mouse anti-Chaoptin (24B10; 1:200) from the Developmental Studies Hybridoma Bank and rabbit anti-GFP (1:5000), anti-rabbit Alexa Fluor-488 (1:250), and anti-mouse Alexa Fluor-555 (1:250) from Invitrogen. Confocal images were collected on a Leica SP2 microscope and analyzed with Leica or Fiji software (http://fiji.sc/Fiji; Schindelin et al.,
2012). All quantifications were performed blind. The " $\%$ R7s that fail to contact M6" $=100 \times($ homozygous R7s that fail to contact M6)/(all homozygous R7s). The "\% R7s with extensions" = $100 \times$ (homozygous $\mathrm{R} 7 \mathrm{~s}$ with extensions)/(all homozygous R7s). The "\% of total extensions" = $100 \times$ (homozygous R7s with extensions in the specified orientation)/(all homozygous $\mathrm{R} 7 \mathrm{~s}$ with extensions). $\mathrm{sev}^{V I}$ animals raised at $25^{\circ} \mathrm{C}$ have considerably fewer R7s than are present in wild type. In particular, we could score $76.7 \pm 4.87$ homozygous syd-1 ${ }^{C D}$ mutant $\mathrm{R} 7 \mathrm{~s}$ per otherwise wild-type brain but only $7.72 \pm 0.68$ homozygous syd- $1^{C D}$ mutant R7s per sev ${ }^{V I}$ mutant brain. As a consequence, there were only $1.80 \pm 0.19$ syd- $1^{C D}$ mutant R7s with extensions per $\operatorname{sev}^{V I}$ mutant brain (instead of the $19.0 \pm 1.64 \mathrm{syd}-1^{C D}$ mutant R7s with extensions in each otherwise wild-type brain). We quantified the total percentages of stops and extensions for each $s v^{V 1}$ brain separately (see Fig. $2 E, F ; n=97$ ) but chose to bin multiple $\operatorname{sev}^{V 1}$ brains together for the purpose of quantifying extension orientation (see Fig. $5 G ; n=7$ ). The binning was random: when the $\operatorname{sev} v^{V 1}$ brains were originally imaged, the data happened to be stored in seven separate folders; we simply binned together data within each folder. $t$ tests were performed (one tailed for rescue experiments and for comparisons between wild type and mutant; two tailed for all other comparisons), and the resulting $p$ values are provided.

Image acquisition and analysis: larval motor axons. Time-lapse imaging was performed in the laboratory of William Saxton at the University of California, Santa Cruz (Santa Cruz, CA). Wandering third-instar larvae were anesthetized as described by Moua et al. (2011). Imaging was initiated at $10-15 \mathrm{~min}$ and terminated at $25-30 \mathrm{~min}$ after anesthesia. Images were collected at two frames per second using a PerkinElmer Life and Analytical Sciences Ultraview spinning-disk confocal microscope. Data analyzed were from larvae that recovered from anesthesia and moved normally for at least $2 \mathrm{~h}$ after being returned to culture. Because Liprin- $\alpha$ is on chromosome 2, we used D42-Gal4, a neuron driver on chromosome 3, to drive ANF-GFP expression in Liprin- $\alpha$ mutants. Analogously, because syd-1 is on chromosome 3, we used OK371-Gal4, a motor neuron driver on chromosome 2, to drive ANF-GFP expression in syd-1 mutants. Images were analyzed with Fiji software (http://fiji.sc/Fiji; Schindelin et al., 2012). All quantifications were performed blind. Flux was calculated by analyzing the movements of fluorescent vesicles within a $20 \mu \mathrm{m}$ region for 200 frames. One-tailed $t$ tests were performed, and the resulting $p$ values are provided.

\section{Results}

\section{Loss of syd-1 causes two defects in R7 axon} terminal morphology

To identify genes required for presynaptic development, we performed a genetic screen using mosaic animals whose R7 neurons were homozygous for randomly mutagenized chromosomes (Lee et al., 2001). We specifically sought mutations that, like loss of Ncad, LAR, or Liprin- $\alpha$, disrupted the ability of R7 axons to form terminal synaptic boutons in the M6 layer. We identified a single such mutation, w46, on chromosome 3R. Wild-type R7 axons terminate in ellipsoid boutons in the M6 layer of the medulla (Fig. 1A). In contrast, most $w 46$ mutant $\mathrm{R} 7$ axon terminals are reduced in size, and many fail to contact the M6 layer altogether (Fig. $1 B$ ). In addition, we noticed that $w 46$ mutant R7 terminals have a second phenotype, distinct from that caused by loss of Ncad, LAR, or Liprin- $\alpha$ : many of the terminals that do contact M6 project thin extensions either beyond or within it (Fig. 1B). These extensions vary in length and orientation, can branch, and often terminate in small, bouton-like varicosities. Mutations that cause R7s to adopt aspects of the R8 fate can cause their axons to lose contact with M6 (Morey et al., 2008). However, we found that $w 46$ mutant R7s express R7-specific and not R8-specific rhodopsins (data not shown), indicating that $w 46$ does not cause this fate transformation and instead specifically disrupts the connectivity of R7 axons.

We mapped $w 46$ by meiotic recombination to a small region that contains the fly homolog of the Caenorhabditis elegans gene 


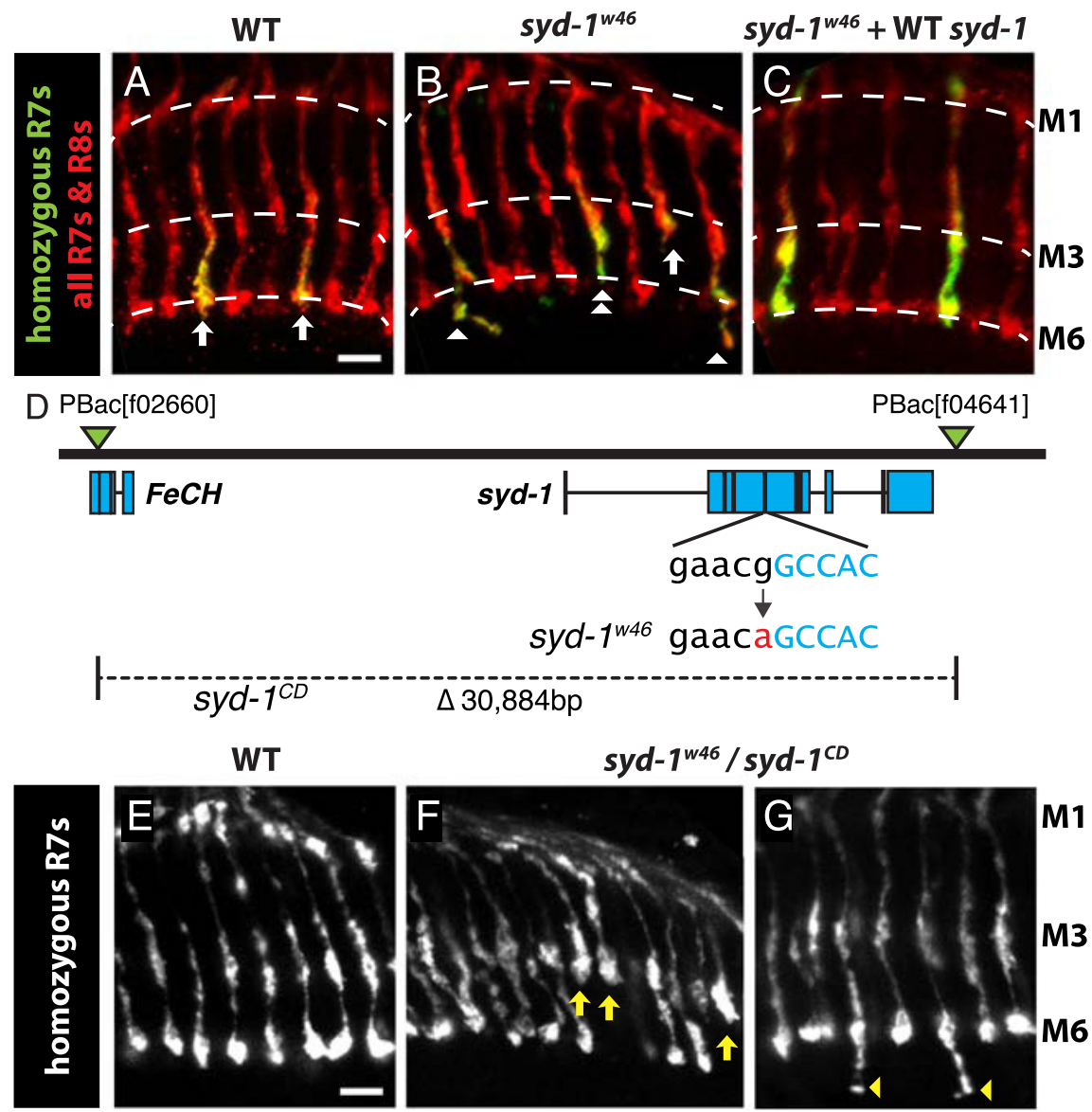

Figure 1. $\quad$ syd-1 is required for normal R7 terminal bouton morphology. A-C, Medullas of adult mosaic animals in which R7s homozygous for the specified chromosome arms express Syt-GFP (green). All R7 and R8 axons are labeled with mAb24B10 (red). Scale bar, $5 \mu \mathrm{m}$. $\boldsymbol{A}$, Each wild-type (FRT82) R7 axon terminates at the M6 layer in an ellipsoidal bouton (arrows). B, syd-1 ${ }^{\text {w46 }}$ mutant R7 axons often fail to contact the M6 layer (arrow). Those that do contact M6 have abnormally small terminal boutons (double arrowhead), which often project thin extensions, many of which terminate in varicosities (arrowheads). C, Expressing a syd-1 CDNA in syd- $7^{w 46}$ mutant R7 axons rescues their morphological defects. D, Schematic representation of the syd- 1 genomic region. The locations of the $P$ elements used to create the $s y d-1^{C D}$ allele are indicated by green triangles. The locations of the ferrochelatase $\left(\mathrm{Fe} C \mathrm{H}\right.$ ) and syd-1 exons are indicated by blue rectangles. The DNA sequence change in the syd- $1^{\text {w } 46}$ allele is indicated (exon sequence is in blue and intron in black), as is the extent of the syd-1 $1^{C D}$ deletion. $\boldsymbol{E}-\boldsymbol{G}$, Medullas of adult animals in which all R7 neurons are of the same genotype and are labeled with PANR7-Gal4, UAS-N-synaptobrevin-GFP (white). The PANR7 promoter drives such high levels of expression that, despite being fused to an SV protein, GFP labels the whole R7 axon. Scale bar, $5 \mu \mathrm{m}$. $\boldsymbol{E}$, Wild-type (FRT82) R7s terminate in ellipsoid boutons at the M6 layer. $\boldsymbol{F}$, Like individual syd- $1^{\text {w46 }}$ mutant R7 axons, R7 axons in syd- $1^{w 46} /$ syd- $1^{C D}$ mutant animals often fail to contact the M6 layer (arrows). G, Like individual syd- $1^{w 46}$ mutant R7 axons, some R7 axon terminals in syd- $1^{w 46} /$ syd- $1^{C D}$ mutant animals project thin extensions beyond M6 (arrowheads).

syd-1 (Hallam et al., 2002). We sequenced the syd-1 locus within the w46 mutant chromosome and found a single base-pair change within a $3^{\prime}$ splice site consensus sequence adjacent to the exon that is predicted to encode part of the RhoGAP homology domain (Fig. 1D). To test whether loss of syd-1 was responsible for all observed defects in w46 mutant R7 axon terminals, we caused the latter to express a wild-type Drosophila syd-1 transgene (for details, see Materials and Methods). We found that this fully restored the morphology of $w 46$ mutant R7 terminals to wild type (Fig. 1C). We conclude that syd-1 is required cell autonomously in R7s both to promote contact between their axon terminals and the M6 layer and to prevent the formation of extensions beyond that layer.

To test whether these phenotypes might be artifacts of creating individual syd-1 mutant R7s, we next wanted to examine whole animals lacking syd-1. To do so, we generated a second allele of $s y d-1$ (which we refer to as $s y d-1^{C D}$ ) by inducing recom- bination between FRT-containing transposons flanking the syd-1 genomic region (Fig. 1D). We found that syd-1 $1^{w 46} / s y d-1^{C D}$ transheterozygous adult animals have normal retinas and that their R7s display the same two axon terminal phenotypes as those described above: decreased contact with the M6 layer and extensions beyond M6 (Fig. 1E-G). We conclude that these defects are independent of our method of creating clones.

The syd-1 and Liprin- $\alpha$ loss-of-function R7 phenotypes are not identical

In worm, loss of syd-1 or Liprin- $\alpha$ causes indistinguishable defects in presynaptic development (Dai et al., 2006; Patel et al., 2006). In contrast, loss of syd-1 from fly NMJ causes a smaller reduction in the number of active zones than does loss of Liprin- $\alpha$ (Owald et al., 2010), indicating that the latter may have syd-1-independent functions. In addition, loss of syd-1 but not Liprin- $\alpha$ from fly NMJ causes postsynaptic defects, indicating that syd-1 in turn has Liprin- $\alpha$-independent functions (Owald et al., 2010, 2012). To investigate the relationship between syd-1 and Liprin- $\alpha$ in $\mathrm{R} 7 \mathrm{~s}$, we first compared their loss-offunction phenotypes.

$s y d-1^{C D}$ fully deletes $s y d-1$ and is therefore a null allele. However, syd-1 ${ }^{C D}$ also removes most of a second gene, ferrochelatase, predicted to encode a mitochondrial enzyme required for the production of heme (Sellers et al., 1998). Because both syd $-1^{C D}$ homozygotes and mosaic animals with entirely $s y d-1^{C D}$ homozygous retinas die before adulthood even when provided with wild-type syd-1, we conclude that loss of ferrochelatase is lethal-at least in combination with loss of syd-1-and that some vital tissue in addition to retina is rendered homozygous in the mosaic animals. Nonetheless, we were able to create individual syd $-1^{C D}$ mutant R7s and found that they have the same defects as those caused by syd-1 $1^{w 46}$ : terminal boutons of reduced size in the M6 layer, failure to contact M6, and thin, sometimes branched, extensions that project beyond or within M6 (Fig. 2A-C). These defects are fully rescued by expression of a wild-type $s y d-1$ transgene within the $s y d-1^{C D}$ mutant R7s (Fig. $2 E, F)$, indicating that none is caused by loss of ferrochelatase. However, the frequencies of the $s y d-1^{C D} \mathrm{R} 7$ defects are slightly greater than that of $s y d-1^{w 46}$ (Fig. $2 E, F$ ), indicating that the $w 46$ allele is non-null.

We next compared the syd-1 ${ }^{C D} \mathrm{R} 7$ defect with that caused by loss of Liprin- $\alpha$ and noted two striking differences: (1) a significantly greater proportion of Liprin- $\alpha$ than syd-1 mutant R7 terminals fail to contact the M6 layer (Fig. 2D,E); and (2) consistent with previous reports (Astigarraga et al., 2010), Liprin- $\alpha$ mutant R7s do not project extensions either beyond or within M6 (Fig. $2 D, F)$. Such differences might theoretically be observed if more wild-type Syd-1 than Liprin- $\alpha$ protein were to perdure in the 

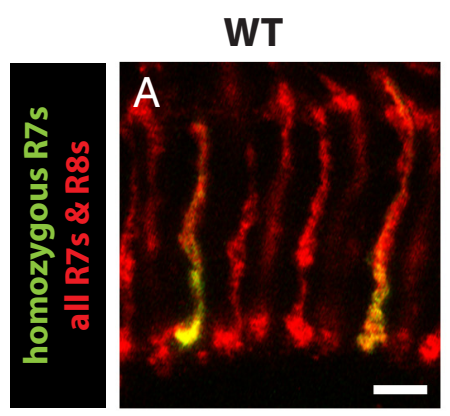

E

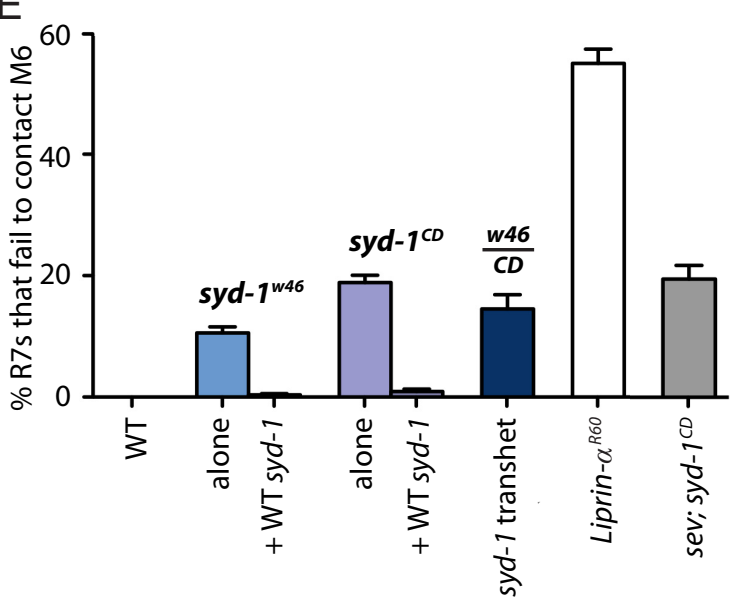

syd-1 ${ }^{C D}$

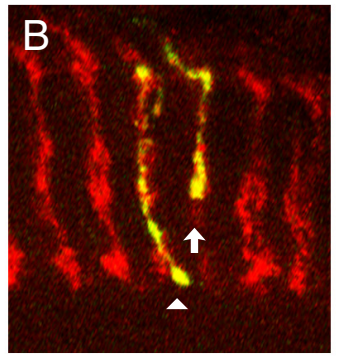

syd-1 ${ }^{C D}$

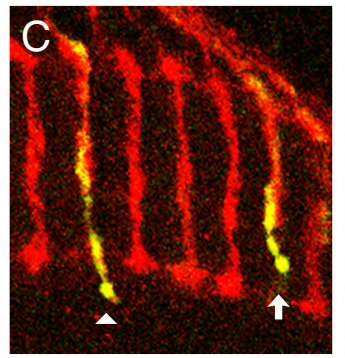

Liprin- $\alpha^{\text {oos }}$

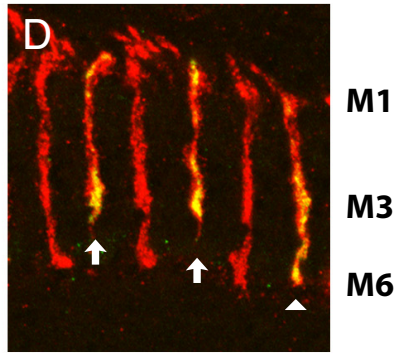

F

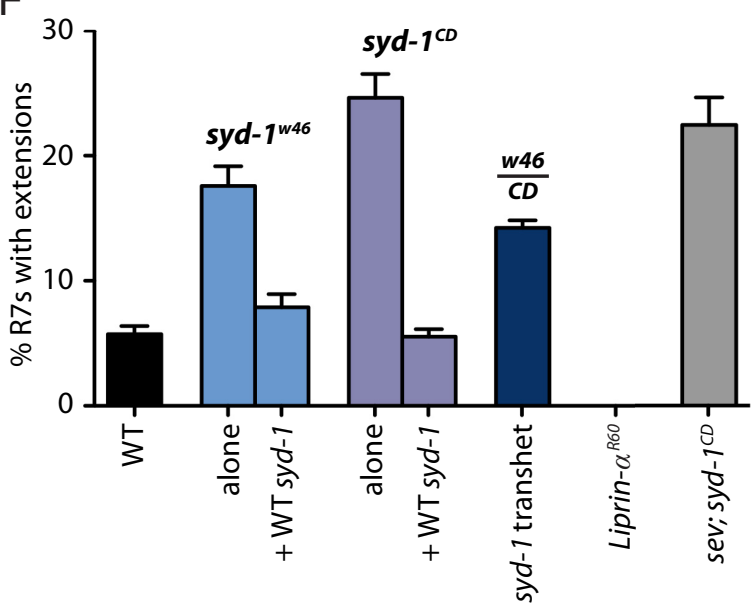

Figure 2. The syd-1 and Liprin- $\alpha$ loss-of-function R7 phenotypes are not identical. $A-D$, Medullas of adult mosaic animals in which homozygous R7s express Syt-GFP (green). All R7 and R8 axons are labeled with mAb24B10 (red). Scale bar, $5 \mu \mathrm{m}$. $\boldsymbol{A}$, Wild-type (FRT82) R7 axons. Like syd- $1^{\text {w46 }}$ mutant R7 axons, R7 axons homozygous for a deletion of syd-1 (syd- $1^{\text {CD }}$ ) often fail to contact the M6 layer ( $\boldsymbol{B}, \boldsymbol{C}$, arrows). Those syd- $\uparrow^{C D}$ axons that do contact M6 have abnormally small terminal boutons ( $\boldsymbol{B}$, arrowhead), which often project thin extensions beyond M6 ( $\boldsymbol{C}$, arrowhead). $\boldsymbol{D}$, Liprin- $\alpha^{R 60}$ mutant R7 axons have abnormally small terminal boutons (arrowhead) and often fail to contact M6 (arrows), but their terminals do not have extensions. $\boldsymbol{E}$, The percentages of wild-type, syd-1, and Liprin- $\alpha$ mutant R7 axons that fail to contact M6. Error bars represent SEM. This syd- $7^{w 46}\left(10.6 \pm 1.00 \% ; n=16\right.$ brains) and syd- $1^{C D}(18.9 \pm 1.25 \% ; n=12$ brains) mutant R7 defect is rescued by expression of a wild-type syd- 1 cDNA (rescue of syd- $1^{w 46}, 0.393 \pm 0.157 \%, n=9$ brains, $p<0.0001$; rescue of syd- $1^{C D}, 0.913 \pm 0.433 \%, n=10$ brains, $p<0.0001$ ). The difference between syd- $1^{C D}$ and syd- $1^{w 46}$ is significant $(p<0.0001)$, as is the difference between syd- $1^{C D}$ and Liprin- $\alpha^{R 60}(55.0 \pm 2.32 \% ; n=9$ brains; $p<0.0001)$. The frequency with which R7s in syd- $1^{w 46} /$ syd- $1^{C D}$ transheterozygous animals fail to contact M6 $\left(14.5 \pm 2.32 \% ; n=7\right.$ brains) is not significantly different from that of individual syd- $1^{\text {w46 }}$ mutant R7s $(p=0.079)$ or of individual syd-1 $1^{C D}$ mutant R7s $(p=0.086)$. Removing adjacent R7s by means of a hypomorphic sev allele has no effect on the frequency with which syd- $1^{C D}$ mutant $R 7 s$ fail to contact M6 $(19.5 \pm 2.28 \% ; n=97$ brains; $p=0.93)$. $\boldsymbol{F}$, The percentages of wild-type, syd-1, and Liprin- $\alpha$ mutant R7 axons that have extensions. Error bars represent SEM. Significantly greater percentages of syd- ${ }^{\text {w } 46}$ ( $17.6 \pm 1.58 \% ; n=16$ brains; $p<0.0001)$ and $s y d-1^{C D}(24.6 \pm 1.89 \% ; n=12$ brains; $p<0.0001)$ mutant R7 terminals have extensions than wild-type R7 terminals $(5.75 \pm 0.638 \% ; n=15$ brains). This defect is rescued by expression of a wild-type syd- 1 cDNA (rescue of syd- $1^{w 46}, 7.89 \pm 1.05 \%, n=9$ brains, $p<0.0001$; rescue of syd- $1^{C D}, 5.55 \pm 0.584 \%, n=10$ brains, $p<0.0001$ ). The difference between syd- $1^{C D}$ and syd- $1^{w 46}$ is significant $(p=0.0078)$, as is the difference between syd- $1^{C D}$ and Liprin- $\alpha^{R 60}(0 \% ; n=9$ brains; $p<0.0001)$. The frequency with which R7s in syd- $1^{w 46} /$ syd- $1^{C D}$ transheterozygous animals have extensions ( $14.2 \pm 0.59 \% ; n=7$ brains) is not significantly different from that of individual syd- $1^{\text {w46 }}$ mutant R7s $(p=0.19)$ but is significantly less frequent than that of individual syd-1 ${ }^{C D}$ mutant R7s $(p<0.001)$. Removing adjacent R7s by means of a sev mutation has no effect on the frequency with which syd- $1^{C D}$ mutant $R 7$ terminals have extensions $(22.5 \pm 2.19 \% ; n=$ 97 brains; $p=0.73$ ).

corresponding individual mutant R7 clones. However, the defects of R7s in $s y d-1^{C D} / s y d-1^{w 46}$ animals are not significantly greater than those of individual syd-1 $1^{w 46}$ mutant R7s (Fig. 2E, F), indicating that wild-type Syd-1 does not perdure in individual syd-1 mutant R7 clones. We therefore conclude that Liprin- $\alpha$ and syd-1 function partly independently of one another during R7 terminal development.

To test the relationship between Liprin- $\alpha$ and syd-1 further, we wanted to create Liprin- $\alpha$; syd-1 double-mutant R7s. Because Liprin- $\alpha$ and syd-1 are on different chromosomes, it is technically difficult to create individual double-mutant R7s. Wholly Liprin- $\alpha$; syd-1 double-mutant animals die as embryos (Owald et al., 2010). We therefore set out to create mosaic animals whose entire retinas were doubly mutant. We found that retinas entirely homozygous for wild-type versions of both chromosome arms (FRT40; FRT82) are grossly normal, as are retinas doubly homozygous for either a Liprin- $\alpha$ mutation and a wild-type syd-1 chromosome arm (Liprin- $\alpha^{R 60}$, FRT40; FRT82) or a wild-type
Liprin- $\alpha$ chromosome arm and a syd-1 mutation (FRT40; FRT82, $\left.s y d-1^{w 46}\right)$. However, retinas doubly mutant for Liprin- $\alpha$ and syd-1 (Liprin- $\alpha^{R 60}$, FRT40; FRT82, syd-1 $1^{w 46}$ ) are severely reduced in size, and the few remaining $\mathrm{R}$ neuron axons in the corresponding medullas are extremely disorganized (data not shown). We conclude that Liprin- $\alpha$ and syd-1 have redundant roles during retina development, and these earlier roles prevent us from determining whether Liprin- $\alpha$ and syd-1 might also have redundant roles in R7 axon terminal development. In the following sections, we describe additional approaches we took to examine the relationship between Liprin- $\alpha$ and Syd-1 during the development of R7 axon terminals.

\section{Unlike loss of Liprin- $\alpha$, loss of syd-1 does not cause a gross defect in axon transport}

syd-1 is required for the localization of Liprin- $\alpha$ to NMJ active zones (Owald et al., 2010), at which Liprin- $\alpha$ is thought to function as a scaffold that localizes additional presynaptic proteins 
(for review, see Stryker and Johnson, 2007). Liprin- $\alpha$ has also been shown to bind Kinesin motor proteins and thereby promote anterograde axon transport of SVs (Shin et al., 2003; Miller et al., 2005; Wagner et al., 2009). We next wanted to test whether syd-1 might similarly be required for normal axon transport or whether Liprin- $\alpha$ instead functions independently of Syd-1 in this process. To do so, we examined movement of the dense-core vesicle marker ANF-GFP in larval motor neuron axons. ANF-GFP particles are large and easy to follow, and their transport has been shown previously to require Kinesin-3/Unc-104/Imac (Barkus et al., 2008), a kinesin that Liprin- $\alpha$ has been shown to bind and regulate in worm (Wagner et al., 2009). We first tested our prediction that loss of Liprin- $\alpha$ would disrupt transport of ANFGFP in Drosophila motor neuron axons. Indeed, we found that Liprin- $\alpha$ mutant animals have significantly fewer ANF-GFP particles moving in the anterograde direction (Fig. $3 A$ ). In contrast, ANF-GFP movement in syd-1 mutant animals is indistinguishable from wild type (Fig. $3 A$ ), suggesting that Liprin- $\alpha$ can promote axon transport independently of Syd-1.

This result suggested a possible explanation for one of the differences between the Liprin- $\alpha$ and syd-1 mutant R7 phenotypes. Because loss of Kinesin-3/Unc-104/Imac prevents presynaptic bouton development at fly NMJ (Pack-Chung et al., 2007), we hypothesized that the Liprin- $\alpha$-specific defect in axon transport might contribute to the increased frequency with which Liprin- $\alpha$ mutant R7s fail to form boutons in M6. If so, we would predict that loss of Kinesin-3/Unc-104/Imac from R7s would disrupt the ability of R7s to form boutons in M6. Indeed, we found that individual imac mutant R7s often fail to contact M6 (Fig. $3 B, C$ ). We did not quantify this phenotype because imac mutant R7 axons frequently lack GFP, preventing us from unambiguously identifying them as such (Fig. $3 C$ and data not shown).

Loss of syd-1 nonetheless disrupts the enrichment of SVs and mitochondria at R7 axon terminals

In worm, both Liprin- $\alpha$ and syd-1 are required for clustering of SVs at en passant synapses (Zhen and Jin, 1999; Hallam et al., 2002; Dai et al., 2006; Patel et al., 2006). To test whether Liprin- $\alpha$ and syd-1 are similarly required for SV clustering at R7 terminal synapses, we used the SV marker Syt-GFP. We found that, in newly eclosed wild-type adults, Syt-GFP predominantly localizes to the region of R7 axons that spans layers M4-M6 of the medulla (Fig. $4 A, A^{\prime}$ ); a smaller amount localizes to the $\mathrm{M} 1$ region of the R7 axon. This pattern is consistent with the known locations of presynaptic sites within R7s (Takemura et al., 2008), suggesting that Syt-GFP accurately reflects the localization of SVs. In contrast, even in syd-1 and Liprin- $\alpha$ mutant R7 axons that contact the M6 target layer, Syt-GFP accumulates in broadly distributed puncta (Fig. $4 B-D^{\prime}$ ). We conclude that, despite the difference between their effects on Kinesin-3/Unc-104/Imac-dependent axon transport [which includes transport of SVs (Pack-Chung et al., 2007; Barkus et al., 2008)], syd-1 and Liprin- $\alpha$ are both required for clustering of SVs in R7 axon terminals.

In addition to active zone proteins and SVs, mitochondria are also enriched at presynaptic sites. We found that, like Syt-GFP, the mitochondrial marker Mito-GFP is enriched in wild-type R7 terminals (Fig. $4 E, E^{\prime}$ ), suggesting that mitochondria are indeed associated with presynaptic sites in R7s. This association is independent of evoked synaptic activity, because Mito-GFP remains localized to the terminals of norpA mutant R7s, in which phototransduction is blocked (Fig. $4 F, F^{\prime}$; Bloomquist et al., 1988; Pearn et al., 1996). In contrast, even in syd-1 and Liprin- $\alpha$ mutant
R7 axons that contact the M6 target layer, Mito-GFP is found in broadly distributed puncta (Fig. 4G-H'). We conclude that $s y d-1$ and Liprin- $\alpha$ are also required for the enrichment of mitochondria at R7 axon terminals. We note that the morphological defects of syd-1 and Liprin- $\alpha$ mutant R7 terminals are unlikely to be an indirect consequence of mitochondrial mislocalization: Miro mutant R7 axon terminals, which completely lack mitochondria (Guo et al., 2005), have wild-type morphology (data not shown).

syd-1 mutant R7 terminals mislocalize SVs and lose contact with M6 during the first half of pupal development; only later do they project extensions

To understand the relationships among the syd-1 mutant R7 defects, we next determined the time course of each. Decreased contact between R7 terminals and the M6 layer can be caused by

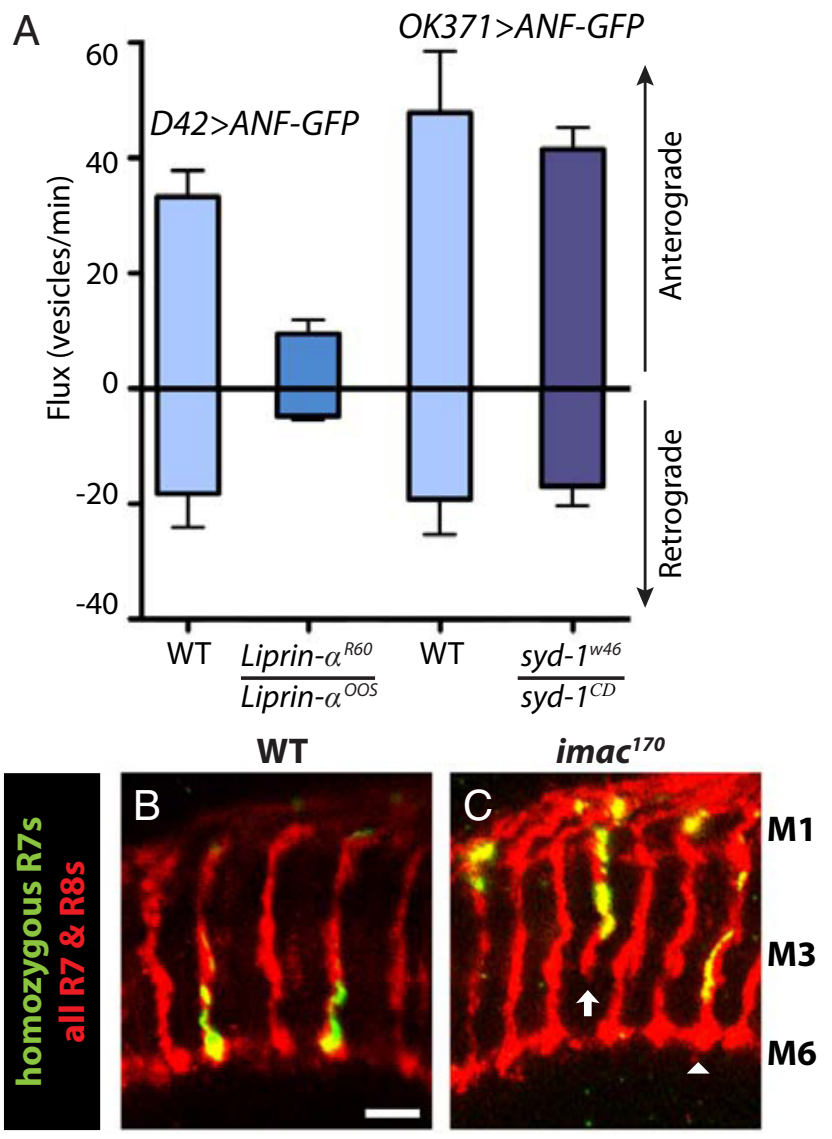

Figure 3. Loss of Liprin- $\alpha$ but not syd-1 significantly disrupts axon transport, which is required for R7 axons to retain contact with M6. A, The number of ANF-GFP-containing vesicles moving in the anterograde or retrograde direction within larval motor neurons of the indicated genotypes. Error bars represent SEM. In Liprin- $\alpha$ mutants, flux in the anterograde direction (9.48 \pm 2.46 vesicles per minute; $n=5$ larvae) is significantly different from that in the matched wild-type control $(33.26 \pm 4.54 ; n=7$ larvae; $p=0.0011)$. Flux in the retrograde direction also appears to differ between Liprin- $\alpha$ mutants ( $4.80 \pm 0.66 ; n=5$ larvae) and wild type (18.26 $\pm 5.78 ; n=7$ larvae), but this difference is only marginally significant ( $p=$ $0.041)$. In syd- 1 mutants, flux in anterograde (41.52 $\pm 3.78 ; n=5$ larvae) and retrograde (16.92 $\pm 3.42 ; n=5$ larvae) directions is not significantly decreased compared with those in the matched wild-type control (anterograde, $47.85 \pm 10.7, n=4$ larvae, $p=0.28$; retrograde, $19.2 \pm 6.1, n=4$ larvae, $p=0.38$ ). $\boldsymbol{B}, \boldsymbol{C}$, Medullas of adult mosaic animals in which homozygous R7s express Mito-GFP (green). All R7 and R8 axons are labeled with mAb24B10 (red). Scale bar, $5 \mu \mathrm{m}$. Unlike wild-type (FRT42) R7 axons ( $\boldsymbol{B}$ ), imac mutant R7 axons often fail to contact the M6 layer ( $\boldsymbol{C}$, arrow). Mito-GFP is frequently mislocalized in or absent from imac mutant $\mathrm{R} 7$ axons ( $\boldsymbol{C}$, arrowhead indicates an imac mutant $\mathrm{R} 7$ axon that forms a terminal bouton in M6 from which Mito-GFP is nonetheless excluded). 

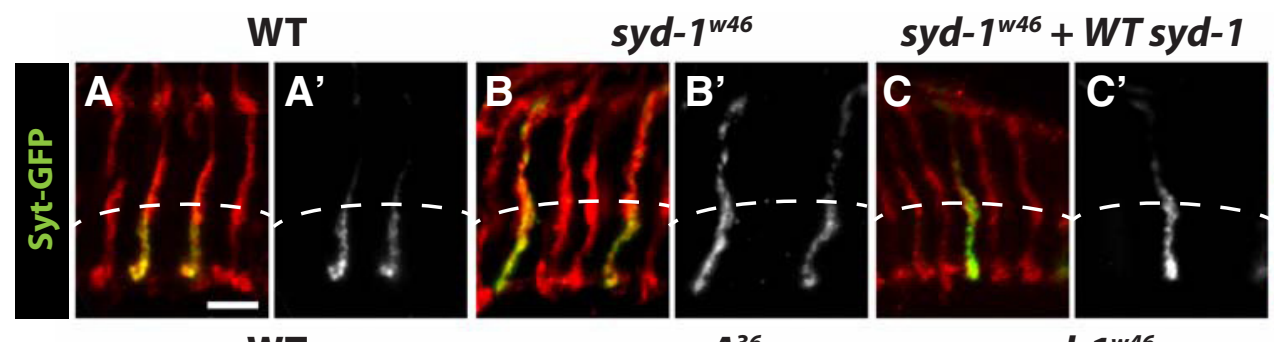

syd-1 ${ }^{\text {w6 }}$
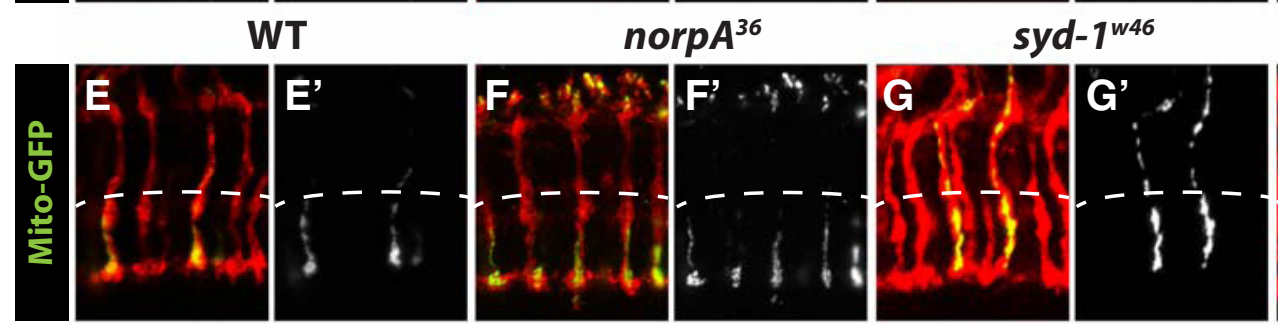

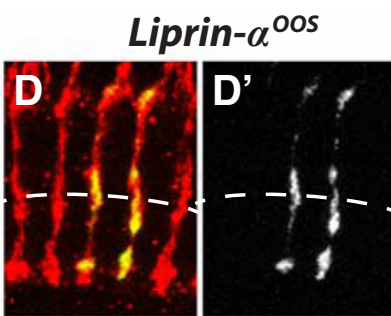

M1

M3

M6

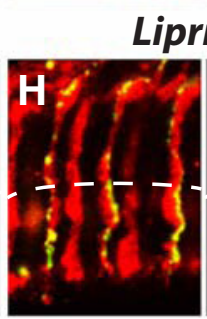

Liprin- $\alpha^{\text {oos }}$

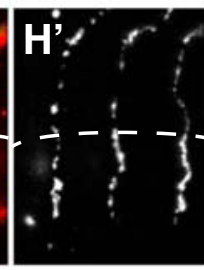

Figure 4. syd-1 and Liprin- $\alpha$ are required for the enrichment of SVs and mitochondria at R7 terminals. $\boldsymbol{A}-\boldsymbol{D}^{\prime}$, Medullas of adult mosaic animals in which homozygous R7s express Syt-GFP (green). All R7 and R8 axons are labeled with mAb24B10 (red). Scale bar, $5 \mu \mathrm{m}$. In wild-type (FRT82) R7s, Syt-GFP is preferentially localized to the region of the axon that lies below the M3 layer ( $\left.\boldsymbol{A}, \boldsymbol{A}^{\prime}\right)$, whereas in syd- $1^{w 46}$ mutant R7 axons, Syt-GFP is more broadly distributed and punctate $\left(\boldsymbol{B}, \boldsymbol{B}^{\prime}\right)$. Syt-GFP is similarly mislocalized in syd- $1^{C D}$ mutant R7s (data not shown). $\boldsymbol{C}, \boldsymbol{C}^{\prime}$, Expressing a syd-1 CDNA in syd-1 mutant R7 axons results in normal localization of Syt-GFP. $\boldsymbol{D}_{,} \boldsymbol{D}^{\prime}$, Syt-GFP is similarly mislocalized and punctate in Liprin- $\alpha$ mutant R7 axons. $\boldsymbol{E}-\boldsymbol{H}^{\prime}$, Medullas of adult mosaic animals in which homozygous R7s express Mito-GFP (green). All R7 and R8 axons are labeled with mAb24B10 (red). $\boldsymbol{E}, \boldsymbol{E}^{\prime}$, In wild-type (FRT82) R7s, Mito-GFP is preferentially localized to the region of the axon that lies below the M3 layer. $\boldsymbol{F}_{,} \boldsymbol{F}^{\prime}$, Mito-GFP remains enriched at R7 terminals even when phototransduction is disrupted by loss of norpA. Note that all R7s in this animal lack norpA and express Mito-GFP (see Materials and Methods). In contrast, in both syd-1 (G, $\left.\mathbf{G}^{\prime}\right)$ and Liprin- $\alpha\left(\boldsymbol{H}, \boldsymbol{H}^{\prime}\right)$ mutant R7 axons, Mito-GFP is broadly distributed and punctate. Expressing a syd-1 CDNA in syd-1 mutant $R 7$ axons results in normal localization of Mito-GFP (data not shown).

at least two different mechanisms: (1) Ncad mutant R7 axons often fail to reach the temporary target layer in the medulla to which R7 axons initially project, and they appear to have collapsed growth cones (Ting et al., 2005), whereas (2) LAR and Liprin- $\alpha$ mutant R7 axons initially reach the temporary target layer and only later lose contact with it (Clandinin et al., 2001; Maurel-Zaffran et al., 2001; Ting et al., 2005; Hofmeyer et al., 2006). To distinguish whether, like Liprin- $\alpha$, syd-1 is not required for R7 axons to initially reach their targets, we examined syd-1 mutant R7 axon terminals at $24 \mathrm{~h}$ after puparium formation (APF), a time point at which $N$ cad mutant R7s display a defect but LAR and Liprin- $\alpha$ mutant R7s do not (Ting et al., 2005; Hofmeyer et al., 2006). We found that wild-type and syd-1 mutant R7 axons are indistinguishable at this stage (Fig. 5A-B'), indicating that syd-1 is not required for R7 axons to reach their temporary target layer and does not affect the gross morphology of R7 terminals at this time point. In addition, the localization of Syt-GFP within wild-type and syd-1 mutant R7 axons at this time is indistinguishable: most Syt-GFP is in the axon terminals (Fig. $\left.5 A-B^{\prime}\right)$, suggesting that the later Syt-GFP puncta in syd-1 mutant R7 axons may reflect a defect in retaining Syt-GFP within these terminals.

We next examined syd-1 mutant $\mathrm{R} 7$ axon terminals at $55 \mathrm{~h}$ APF. Unlike wild-type R7 terminals at this stage (Fig. $5 C, C^{\prime}$ ), syd-1 mutant R7 terminals are abnormally small and often fail to contact the M6 layer, and Syt-GFP is mislocalized in broadly distributed puncta (Fig. 5D, $D^{\prime}$ ). We conclude that, like Liprin- $\alpha$, syd-1 is required for the interaction between R7 terminals and their final target layer M6 and that both this interaction and the clustering of Syt-GFP at presynaptic sites within R7 terminals normally occur between 24 and $55 \mathrm{~h}$ APF.

By $55 \mathrm{~h} \mathrm{APF}$, the percentages of $s y d-1^{w 46}$ and $s y d-1^{C D}$ mutant $\mathrm{R} 7$ axons that fail to contact M6 are maximal (Fig. $5 E$ ). However, syd-1 mutant R7 terminals do not project extensions at this time point (Fig. $\left.5 D, D^{\prime}, F\right)$. Instead, those syd-1 mutant terminals that do contact M6 terminate in smooth boutons of reduced size (Fig. $\left.5 D, D^{\prime}\right)$. We conclude that (1) the extensions observed in adult occur at a later time point than the failure to contact M6 and the mislocalization of Syt-GFP, and (2) the extensions are formed by an active process rather than by a failure to retract or remodel growth cone filopodia. By $72 \mathrm{~h}$ APF, the percentage of $s y d-1^{w 46}$ mutant R7 terminals that have extensions is maximal and the percentage of $s y d-1^{C D}$ mutant R7 terminals with extensions is significantly greater than that in wild-type (Fig. $5 F$ ). We conclude that the extension process is initiated between 55 and $72 \mathrm{~h} \mathrm{APF}$ and note that the infrequent R7 extensions observed in wild type also appear during this period.

Previous work has shown that R7 axon terminals are mutually repulsive (Ashley and Katz, 1994; Ting et al., 2007). We noticed that both wild-type and syd-1 mutant R7 terminals project extensions primarily in the forward orientation (i.e., beyond the M6 layer) rather than laterally (i.e., within or parallel to M6; Fig. 5G). We therefore wondered whether these extensions were prevented from projecting laterally by repulsion from neighboring R7 terminals. To test this, we used a hypomorphic sev allele to eliminate most R7s (Mullins and Rubin, 1991). We found that those isolated syd-1 mutant R7s that remain still fail to contact M6 (Fig. $2 E$ ) and project extensions (Fig. $2 F$ ) at the same frequencies and that the orientation of their extensions does not change (Fig. 5G). We conclude that syd-1 mutant R7 extensions are unaffected by repulsion by neighboring $\mathrm{R} 7$ axons and instead have an intrinsic propensity to orient forward.

Overexpressing Liprin- $\alpha$ in syd-1 mutant R7s restores their contact with the M6 layer but does not prevent the formation of extensions; overexpressing Liprin- $\beta$ has no effect on $s y d-1$ mutant R7 terminals

In worm, loss of syd-1 is fully rescued by Liprin- $\alpha$ overexpression, suggesting that the primary role of Syd-1 is to localize or otherwise activate Liprin- $\alpha$ (Dai et al., 2006; Patel et al., 2006; Patel and Shen, 2009). To test whether the same might be true in R7s, we used the act promotor to overexpress Liprin- $\alpha$ in individual syd$1^{C D}$ mutant R7s (the same methodology that we used to show that Syd-1 fully rescues syd-1 ${ }^{C D}$ mutant R7s). We found that Liprin- $\alpha$ 
WT
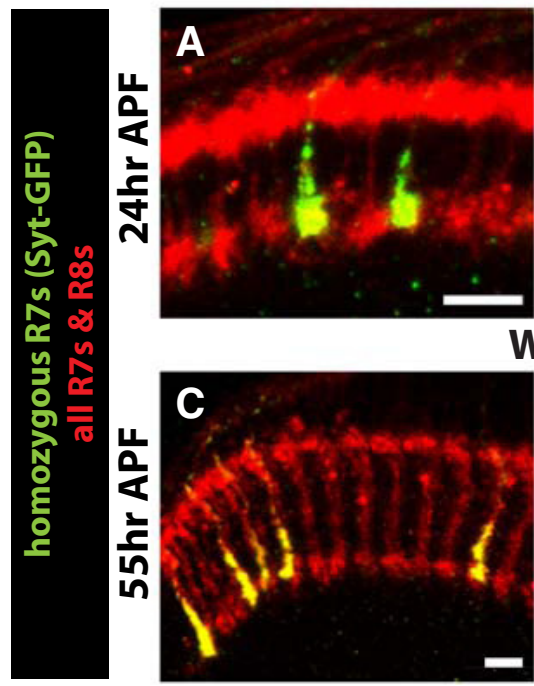

WT

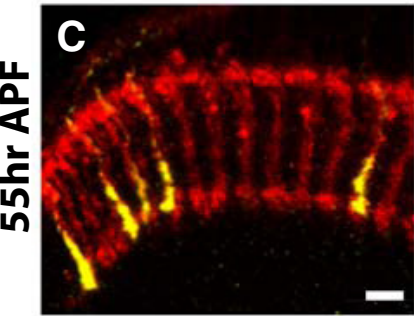

E

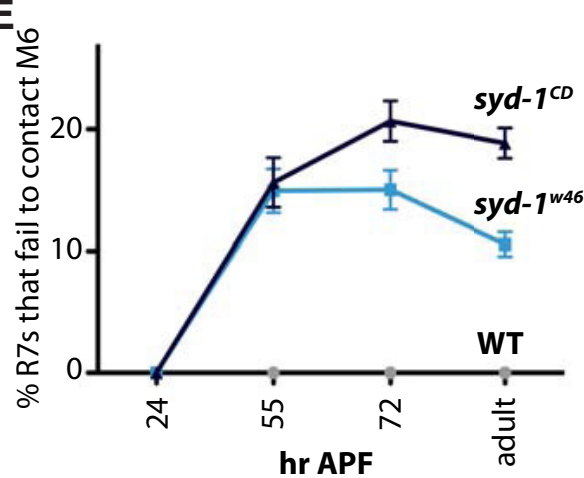

TT
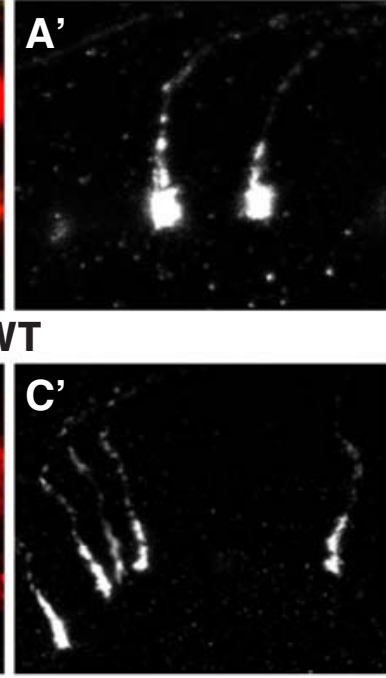

$F$

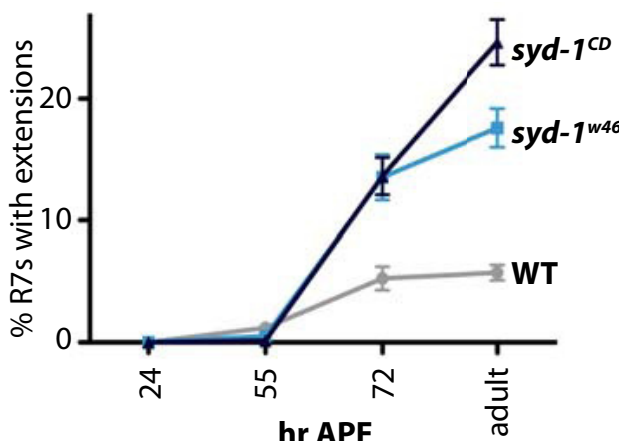

syd-1 ${ }^{\text {w6 }}$
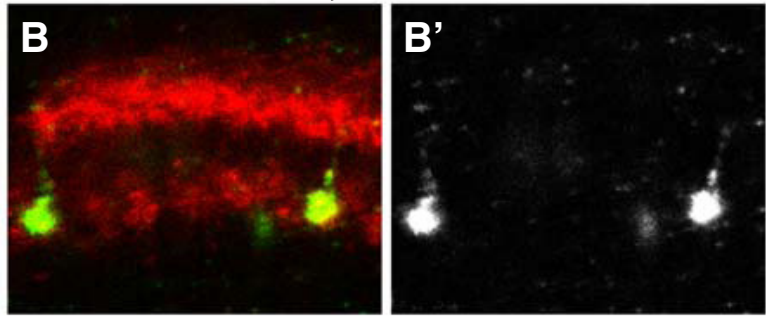

syd-1 ${ }^{w 46}$
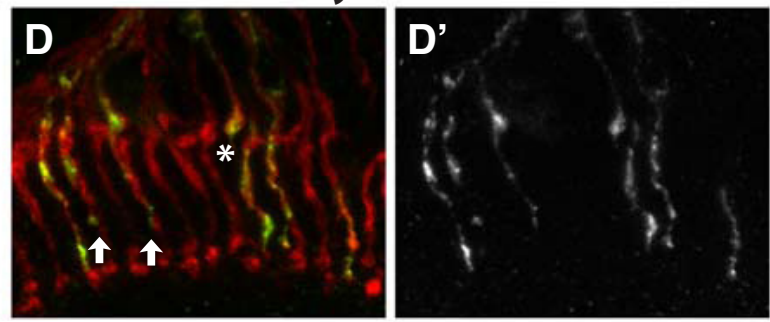

G

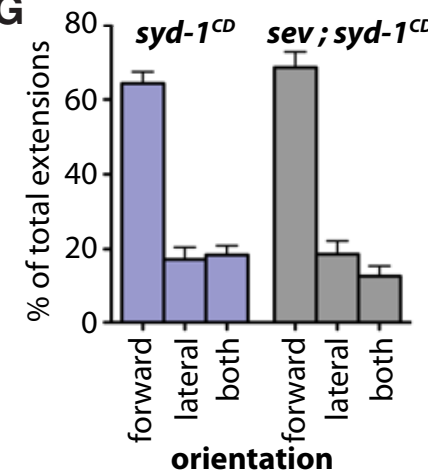

Figure 5. syd-1 mutant R7 terminals first lose contact with M6 and only later project extensions. $\boldsymbol{A}-\boldsymbol{D}^{\prime}$, Medullas of mosaic pupae in which homozygous R7s express Syt-GFP (green). All R7 and R8 axons are labeled with mAb24B10 (red). Scale bars, $5 \mu \mathrm{m}$. At $24 \mathrm{~h} \mathrm{APF,} \mathrm{wild-type}\left(\boldsymbol{A}, \boldsymbol{A}^{\prime}\right)$ and syd-1 mutant $\left(\boldsymbol{B}, \boldsymbol{B}^{\prime}\right)$ R7 axons are indistinguishable: their growth cones have similar morphology, they terminate in the R7 target layer, and Syt-GFP is enriched within their terminals. By $55 \mathrm{~h}$ APF $\left(\boldsymbol{C}-\boldsymbol{D}^{\prime}\right)$, syd-1 mutant R7 terminals often fail to contact the R7 target layer ( $\boldsymbol{D}$, arrows), those that do contact M6 have smaller boutons than wild type, and Syt-GFP is mislocalized and punctate. However, neither wild-type nor syd-1 mutant R7 terminals have extensions at this time point. The asterisk in $\boldsymbol{D}$ indicates a syd-1 mutant R7 axon that appears to terminate in M1 but that in fact extends to M6 in focal planes not included in this image. $\boldsymbol{E}$, The percentages of wild-type and syd-1 mutant R7 axons that fail to contact the R7 target layer at 24, 55, and 72 h APF and in adult. Error bars represent SEM. At 24h APF, all wild-type and syd-1 mutant R7s contact the R7 target layer (wild type, $n=5$ brains; syd- $1^{w 46}, n=9$ brains; syd $-1^{C D}, n=10$ brains). However, by $55 \mathrm{~h} \mathrm{APF}, 14.9 \pm 1.80 \%$ ( $n=12$ brains) of syd- $1^{w 46}$ and $15.6 \% \pm 2.03 \%$ ( $n=11$ brains) of syd- $1^{C D}$ R7s $n$ o longer do so. The percentages of syd -1 mutant R7 axons with this defect are not significantly different at $72 \mathrm{~h} \mathrm{APF}$ (syd- $1^{\text {w }}{ }^{6}, 15.0 \pm 1.61 \%, n=12 \mathrm{brains}, p=0.97 ;$ syd- $1^{C D}, 20.7 \pm 1.66 \%, n=12$ brains, $p=0.067$ ), nor does the percentage of syd- $1^{C D}$ mutant R7s with this defect change significantly between $72 \mathrm{~h}$ APF and adulthood $[p=0.39 ;$ the difference between the $55 \mathrm{~h}$ APF and adult percentages is also insignificant $(p=0.18)$ ]. However, the percentage of syd- $1^{\text {w46 }}$ mutant R7s with this defect may decrease slightly between $72 \mathrm{~h}$ APF and adulthood $[p=0.021$; the decrease between the $55 \mathrm{~h} \mathrm{APF}$ and adult percentages is also marginally significant $(p=0.032)]$. The adult data used are the same as that in Figure $2 E$ and are redisplayed here for ease of comparison. $\boldsymbol{F}$, The percentages of wild-type and syd- 1 mutant R7 axon terminals that have extensions at 24,55, and $72 \mathrm{~h}$ APF and in adult. Error bars represent SEM. At $24 \mathrm{~h}$ APF, wild-type and syd-1 mutant R7 axon terminals are indistinguishable (wild type, $n=5$ brains; syd- $1^{w 46}, n=9$ brains; syd- $1^{C D}, n=10$ brains). By $55 \mathrm{~h}$ APF, a small percentage of wild-type R7s ( $1.20 \pm 0.404 \% ; n=12$ brains) have short extensions beyond their target layer. At this time point, the percentage of syd- $7^{w 46}$ mutant R7s with extensions $(0.528 \pm 0.276 \% ; n=12$ brains) is not significantly different from that of wild type $(p=0.18)$, and the percentage of syd- $1^{C D}$ mutant $\mathrm{R} 7 \mathrm{~s}$ with this defect $(0.145 \pm 0.15 \% ; n=11$ brains) may be slightly lower than that of wild type ( $p=0.027)$. By $72 \mathrm{~h}$ APF, a significantly greater percentage of syd-1 $1^{w 46}(13.5 \pm 1.87 \% ; n=12$ brains; $p<0.001)$ and syd- $1^{C D}(13.6 \pm 1.54 \% ; n=12$ brains; $p<0.0001)$ mutant R7s have extensions than do wild-type R7s. The percentage of syd- $1^{w 46}$ mutant R7s with this defect does not change significantly between $72 \mathrm{~h}$ APF and adulthood $(p=0.11)$. However, the percentage of syd- $1^{C D}$ mutant R7s with this defect increases significantly during this period $\left(p<0.001\right.$ ). The adult data used are the same as that in Figure $2 E$ and are redisplayed here for ease of comparison. $\mathbf{G}, 0$ f those syd- $1^{C D}$ mutant $R 7$ axon terminals that have extensions, the percentages whose extensions project forward, laterally, or both (R7s with both have either a single extension that projects both forward and laterally or two extensions of which one projects forward and the other laterally). Removing adjacent R7s by means of a sev mutation has no significant effect on the orientation of syd- ${ }^{C D}$ mutant $R 7$ extensions [in the presence of neighboring R7s, $64.3 \pm 3.14 \%$ extend forward, $17.3 \pm 3.23 \%$ extend laterally, and $18.5 \pm 2.49 \%$ have extensions in both directions ( $n=14$ brains); in the absence of neighboring R7s, $68.6 \pm 4.15 \%$ extend forward ( $p=0.42), 18.6 \pm 3.56 \%$ extend laterally $(p=0.79)$, and $12.8 \pm 2.71 \%$ have extensions in both directions $(p=0.17) ; n=7$ sets of data binned from multiple brains (for details, see Materials and Methods)].

overexpression significantly increases contact between syd-1 mutant R7 terminals and the M6 layer (the defect is reduced by $49 \%$; Fig. $6 A, B, D)$, indicating that increased Liprin- $\alpha$ can partially bypass the requirement for syd-1 during the early phase of R7 terminal development. However, Liprin- $\alpha$ overexpression has no effect on the later tendency of syd-1 mutant R7s to project extensions (Fig. 6A, $B, E$ ); instead, the overall frequency of extensions is increased by the amount predicted given the larger proportion of terminals that contact M6 and therefore have the opportunity to extend within or beyond it. These results suggest that Syd-1 does not prevent extensions by localizing or otherwise activating Liprin- $\alpha$ and that therefore the early and late defects in syd-1 mutant R7 terminal morphology are caused by different molecular mechanisms.

Previous work has shown that a second Liprin protein, Liprin- $\beta$, acts in parallel with Liprin- $\alpha$ in R7s (Astigarraga et al., 
2010). R7s lacking both Liprin- $\alpha$ and Liprin- $\beta$ have a combination of the defects caused by loss of either alone: failure of their axons to contact M6 and projection of extensions beyond M6 (Astigarraga et al., 2010). The similarity of this phenotype to that caused by loss of Syd-1 suggested that, whereas Liprin- $\alpha$ acts downstream of Syd-1 to promote contact with M6, Liprin- $\beta$ might in parallel act downstream of Syd-1 to prevent extensions. If so, we would predict that overexpressing Liprin- $\beta$ in individual syd-1 $1^{C D}$ mutant R7s would rescue the syd-1 mutant R7 extensions. However, we found that Liprin- $\beta$ overexpression had no effect on either the frequency of contact with M6 or the frequency of extensions (Fig. 6D,E), suggesting that Syd-1 does not prevent extensions by positively regulating Liprin- $\beta$.

Syd-1 acts upstream of Trio in R7s to both promote contact with M6 and prevent extensions

Trio, a GEF for Rac and Rho, is a key positive regulator of presynaptic development in fly (Ball et al., 2010). Trio overexpression rescues the R7 defects caused by loss of LAR (Maurel-Zaffran et al., 2001) and both the NMJ and R7 defects caused by loss of Liprin- $\alpha$ or Liprin- $\beta$ (Astigarraga et al., 2010), suggesting that Trio acts downstream of these genes. We next tested whether Trio overexpression could also compensate for loss of syd-1. Indeed, using the act promoter to drive trio expression almost completely restores the ability of $s y d-1^{C D}$ mutant R7s to maintain contact with M6 (the defect is reduced by 91\%; Fig. 6C,D) and significantly reduces the frequency of extensions (by 35\%; Fig. $6 C, E)$. These results suggest that trio acts downstream of syd-1 during both the early and late phases of R7 terminal development and that, unlike Liprin- $\alpha$, trio mediates most or possibly all of the effects of syd-1. If so, then loss of trio should resemble loss of syd-1. However, reducing trio function in R7s using RNAi was previously found only to cause extensions beyond M6 and not to disrupt the ability of R7s to contact M6 (Astigarraga et al., 2010). To remove trio function more completely from R7s, we created individual homozygous trio mutant R7s. Consistent with trio mediating both the early and late effects of $s y d-1$, we found that trio mutant terminals displayed the same two morphological defects as those of syd-1 mutant R7s: $13.9 \pm 2.58 \%(n=8$ brains $)$ of trio $^{3}$ mutant R7s failed to contact the M6 layer (Fig. 7A), and $15.5 \pm 1.94 \%$ ( $n=8$ brains) had extensions beyond M6 (Fig. $7 B$ ). The lower frequencies of the trio defects are likely caused by perdurance of wild-type Trio within trio mutant clones: Trio protein is expressed broadly during eye development and is required early in $\mathrm{R}$ neuron development for axon pathfinding (Newsome et al., 2000).

To further test whether syd-1 and trio might function in the same pathway, we next tested whether syd-1 and trio also have similar gain-of-function effects on R7 terminals. Overexpression of Trio has been shown previously to rescue loss of the LAR receptor phospha-

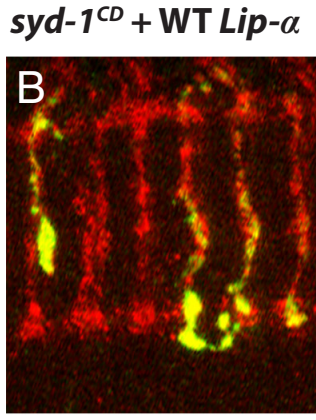

syd-1 ${ }^{C D}+$ WT trio

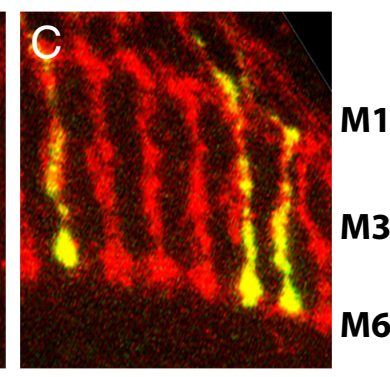

E

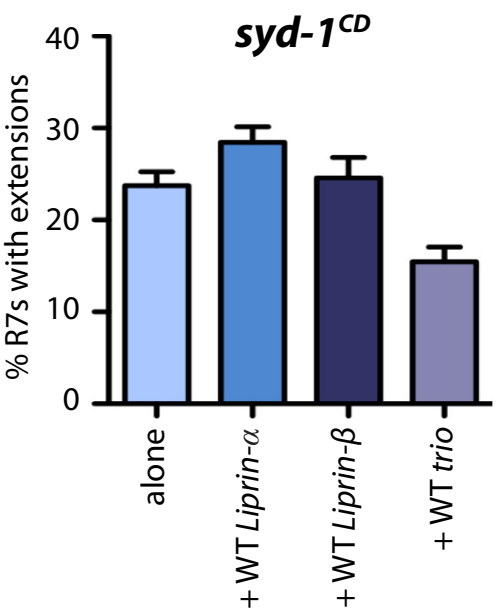

Figure 6. Overexpressing Liprin- $\alpha$, Liprin- $\beta$, or Trio in syd-1 mutant R7s rescues their defects to different degrees. $\boldsymbol{A}-\boldsymbol{C}$, Medullas of adult mosaic animals in which homozygous R7s express Syt-GFP (green), and all R7 and R8 axons are labeled with mAb24B10 (red). Scale bar, $5 \mu \mathrm{m} . \boldsymbol{A}$, syd- $7^{C D}$ mutant R7 axons. $\boldsymbol{B}$, Expressing Liprin- $\alpha$ in syd $-1^{C D}$ mutant $R 7$ axons partially restores their contact with M6 but does not prevent the formation of extensions. C, Expressing trio in syd- $1^{C D}$ mutant R7 axons completely restores their contact with $M 6$ and considerably decreases the frequency of extensions. $D$, The percentages of syd- $1^{C D}$ mutant $R 7$ axons that fail to contact M6 when overexpressing no transgene, wild-type Liprin- $\alpha$, wild-type Liprin- $\beta$, or wild-type trio. Error bars represent SEM. This syd- $1^{C D}$ mutant R7 defect (22.3 $1.36 \%, n=21$ brains) is partially rescued by expression of Liprin- $\alpha(11.3 \pm 1.33 \% ; n=14$ brains; $p<0.0001)$, fully rescued by that have extensions when overexpressing no transgene, wild-type Liprin- $\alpha$, wild-type Liprin- $\beta$, or wild-type trio. Error bars represent SEM. This syd-1 $1^{C D}$ mutant R7 defect ( $23.7 \pm 1.52 \% ; n=21$ brains) is partially rescued by expression of trio $(15.5 \pm 1.59 \% ; n=15$ brains; $p<0.001)$ but is not rescued by expression of Liprin- $\alpha(28.4 \pm 1.70 \% ; n=14$ brains; $p=0.052)$ or Liprin- $\beta(24.6 \pm 2.22 \% ; n=13$ brains; $p=0.38)$. The difference between rescue by Liprin- $\alpha$ and trio is significant $(p<0.0001)$.

tase (Maurel-Zaffran et al., 2001). If syd-1 promotes R7 terminal development by potentiating trio activity, then we would expect that Syd-1 overexpression should also rescue loss of LAR. Indeed, we found that overexpressing syd-1 or trio in $L A R$ mutant R7s restored contact with the M6 layer to indistinguishable degrees (the defect was reduced by $34 \%$ in both cases; Fig. $7 C-F$ ). Together, these results are consistent with a model in which the primary role of syd-1 during both early and late phases of R7 presynaptic development is to promote trio activity.

\section{Discussion}

\section{Localization of SVs in R7s}

GFP-fused SV proteins, such as Syt-GFP, are classic tools for studying presynaptic development but have not been used previously to analyze R7s. We found that, as expected, Syt-GFP within $\mathrm{R} 7 \mathrm{~s}$ is enriched at sites known by electron microscopy to contain active zones (Takemura et al., 2008). Loss of LAR, Liprin- $\alpha$, or syd-1 causes R7 terminals to fail to contact their normal, M6, target layer. We demonstrate here that this morphological defect correlates temporally with a failure to localize SVs to presynaptic 


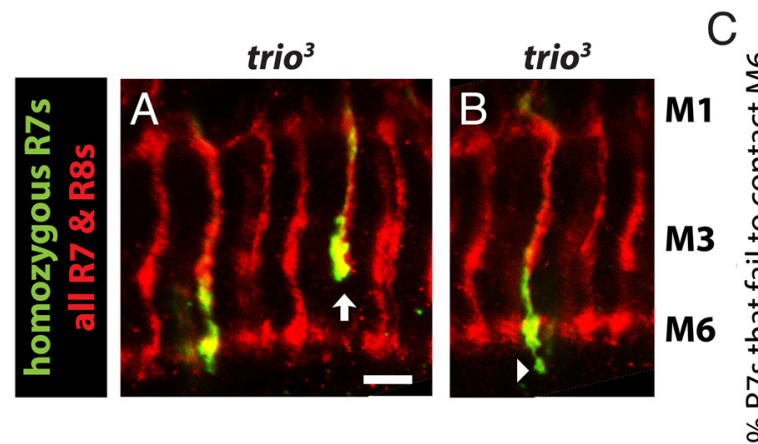

$\operatorname{LAR}^{2127}$
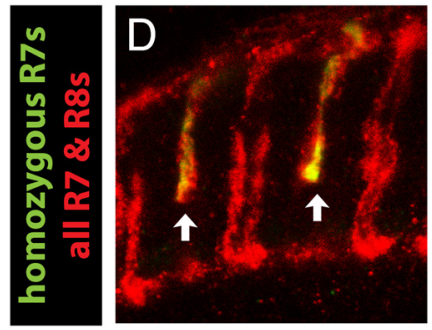
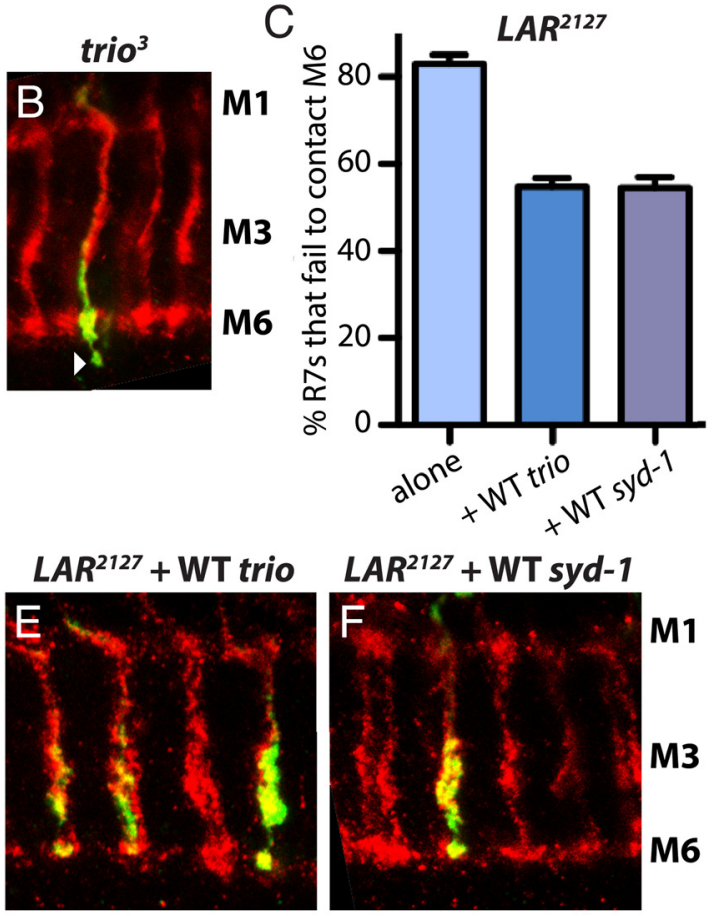

Localization of mitochondria in R7s

Although mitochondria are often enriched at synapses, it remains unclear what proportion of them might be stably associated with presynaptic sites rather than transported there in response to acute energy needs. Within at least some axons, most clusters of stationary mitochondria reside at nonsynaptic sites (Louie et al., 2008). In R7s, we found that Mito-GFP is enriched at presynaptic sites. Because arthropod photoreceptor neurons continuously release neurotransmitter in response to light (Stuart et al., 2007), this enrichment might simply be caused by continuous energy needs. However, we found that mitochondria remained enriched at R7 terminals even in the absence of light-evoked activity, indicating that either spontaneous release is sufficient for their recruitment or an activityindependent mechanism is responsible. We speculate that the permanently high energy demands at photoreceptor synapses may have selected for the activityindependent association of mitochondria with R7 synapses and that this localization requires syd-1 and Liprin- $\alpha$. We found that Mito-GFP is mislocalized in imac mutant R7s, despite previous work indicating that Kinesin-3/Unc-104/Imac is not required for transport of mitochondria (Pack-Chung et al., 2007; Barkus et al., 2008). One interpretation is that mitowhich homozygous R7s express Syt-GFP (green), and all R7 and R8 axons are labeled with mAb24B10 (red). Scale bar, $5 \mu \mathrm{m}$. trio ${ }^{3}$ mutant R7s often fail to contact the M6 layer ( $\boldsymbol{A}$, arrow) and project thin extensions beyond M6 (B, arrowhead). trio ${ }^{7}$ mutant R7 have the same two defects but at a lower frequency (data not shown). $C$, The percentages of $L A R^{2127}$ mutant $R 7$ axons that fail to contact M6 when overexpressing no transgene, wild-type trio, or wild-type syd-1. Both Trio and Syd-1 significantly rescue this defect. Error bars represent SEM. The $L A R^{2127}$ mutant $\mathrm{R} 7$ defect $(83.0 \pm 2.09 \% ; n=11$ brains) is partially rescued by expression of trio $(54.8 \pm 1.99 \% ; n=10$ brains; $p<0.0001)$ or syd $-1(54.6 \pm 2.37 \% ; n=10$ brains; $p<0.0001)$. The difference between rescue by syd- 1 or trio is not significant ( $p=0.95) . D, L A R^{2127}$ mutant R7 axons fail to contact the M6 layer (arrows). Expressing trio $(\boldsymbol{E})$ or syd- $1(\boldsymbol{F})$ in $L A R^{2127}$ mutant $\mathrm{R} 7$ axons restores their contact with $\mathrm{M} 6$ to similar degrees.

sites and is therefore likely to reflect a defect in R7 presynaptic development rather than simply in target layer selection.

Liprin- $\alpha$ is not only a scaffold for the assembly and retention of presynaptic components, including SVs, at presynaptic sites (for review, see Stryker and Johnson, 2007) but also a positive regulator of Kinesin-3/Unc-104/Imac-dependent axon transport of those components (Shin et al., 2003; Miller et al., 2005; Wagner et al., 2009). We here show that, unlike Liprin- $\alpha$, Syd-1 is not required for normal Kinesin-3/Unc-104/Imac-mediated transport. However, SVs are similarly mislocalized in Liprin- $\alpha$ and syd-1 mutant R7 axons that contact M6. A simple interpretation is that this mislocalization reflects a requirement for Liprin- $\alpha$ and syd-1 in retaining SVs within R7 terminals; in support of this, we found that SVs are localized normally to syd-1 mutant R7 axon terminals at $24 \mathrm{~h} \mathrm{APF}$, before synaptogenesis. We hypothesize that the additional disruption of axon transport in Liprin- $\alpha$ mutant R7s is reflected in their greater inability to maintain contact with M6; in support of this, we found that imac mutant R7 axons also lose contact with M6.

Although both Liprin- $\alpha$ and syd-1 are required for the clustering of SVs at en passant synapses in worm (Zhen and Jin, 1999; Hallam et al., 2002; Dai et al., 2006; Patel et al., 2006), syd-1 is not required for the localization of SVs to NMJ terminals in fly (Owald et al., 2010). The molecular mechanisms underlying presynaptic development at NMJ and in R7s have been shown previously to differ in several respects (Hofmeyer and Treisman, 2009; Astigarraga et al., 2010). Our finding further highlights the importance of analyzing synapse development using multiple neuron types. chondria are normally tethered at R7 presynaptic sites and that loss of imac indirectly causes their mislocalization by disrupting transport of the components required for tethering to occur.

Two distinct phenotypes are caused by disrupting presynaptic development in R7s

Previous work identified two different phenotypes associated with loss of the LAR/Liprin/trio pathway: loss of LAR or Liprin- $\alpha$ caused R7 axons to terminate before their M6 target layer, whereas loss of Liprin- $\beta$ or trio caused R7 axons to project extensions beyond M6. One possibility is that these two defects are simply different manifestations of the same cellular defect: a decrease in the stability of the synaptic contact between R7s and their targets (Astigarraga et al., 2010). However, we have shown here that loss of a single gene, syd-1, causes both defects and that the defects occur at distinct developmental time points, suggesting that they occur by distinct mechanisms. In support of this, Liprin- $\alpha$ overexpression can rescue the early but not the late $s y d-1$ defect.

The earlier defect, failure to contact M6, correlates with the failure to localize SVs, suggesting, as mentioned above, that this represents a failure to assemble synapses. However, the cause of the later morphological defect and the precise nature of the extensions remain unclear. We note that the extensions often terminate in small varicosities that can contain Syt-GFP (Figs. 1B, 2C) and Mito-GFP (data not shown), indicating that they are not simply filopodia but may instead represent sites of ectopic presynaptic assembly. One possibility is that, as at NMJ (Owald et al., 2010, 2012), loss of syd- 1 causes ectopic accumulations of Liprin- $\alpha$, Brp, Nrx-1, or other presynaptic proteins and that these might then promote ecto- 
pic, abnormal presynaptic assembly. A second possibility is that the extensions may instead be an indirect consequence of the role of syd-1 in postsynaptic development (Owald et al., 2010, 2012): perhaps the extensions are the response of the syd-1 mutant R7 terminal to defects in its postsynaptic target. Loss of Liprin- $\alpha$ causes no such postsynaptic effect, providing an explanation for why Liprin- $\alpha$ mutant R7s do not form extensions. A third possibility is that R7s form distinct types of synapses at different time points. Failure to assemble one type of synapse, which R7s assemble first, causes decreased contact with M6, whereas failure to assemble a second type, which occur later, results in extensions. Consistent with this model, R7s form synapses with more than one neuron type (Gao et al., 2008; Morante and Desplan, 2008; Takemura et al., 2008).

\section{The relationship between syd-1 and Liprin- $\alpha$}

Loss of syd-1 has a significantly weaker effect on fly NMJ development than does loss of Liprin- $\alpha$ (Owald et al., 2010). Likewise, here we show that the early phase of R7 terminal development, during which presynaptic components are localized, is less affected by loss of $s y d-1$ than by loss of Liprin- $\alpha$. We identify a possible explanation for this difference: loss of Liprin- $\alpha$, but not of syd-1, significantly decreases Kinesin-3/ Unc-104/Imac-mediated axon transport, and Kinesin-3/Unc104/Imac is required for R7s to form boutons in M6.

In both worm and fly, Syd-1 is required for the normal localization of Liprin- $\alpha$ and Brp/ELKS to presynaptic sites (Dai et al., 2006; Patel et al., 2006; Patel and Shen, 2009; Owald et al., 2010). In worm, loss of syd-1 can be rescued either by overexpressing full-length wildtype Liprin- $\alpha$ (Dai et al., 2006; Patel et al., 2006), or by overexpressing a domain of Liprin- $\alpha$ that promotes oligomerization of Liprin- $\alpha$ proteins (Taru and Jin, 2011), or by a mutation that enhances the ability of Liprin- $\alpha$ to bind Brp/ELKS (Dai et al., 2006). These results suggest that the primary function of Syd-1 is to potentiate Liprin- $\alpha$ activities. However, we found that Liprin- $\alpha$ overexpression only partially rescues the early defect that syd-1 mutant R7s have in assembling synapses. This suggests that, as in worm, Liprin- $\alpha$ can act partly independently of Syd-1 during presynaptic assembly but that, unlike in worm, Syd-1 also has some Liprin- $\alpha$-independent function. In contrast, Liprin- $\alpha$ overexpression does not at all rescue the late extensions caused by loss of syd-1. As we speculate above, one possibility is that these extensions might be caused by mislocalized Liprin- $\alpha$, Brp, or Nrx-1.

\section{The relationship between syd-1 and trio}

Unlike Liprin- $\alpha$, Trio overexpression fully rescues the early and partly rescues the late defect caused by loss of syd-1, suggesting that Syd-1 promotes R7 synaptic terminal development primarily by potentiating Trio activity. Consistent with this model, loss of trio phenocopies loss of syd-1 from R7s, and overexpressing Syd-1 or Trio bypasses the need for LAR to similar degrees. At fly NMJ, Trio promotes presynaptic development by acting as a GEF for Rac1 (Ball et al., 2010). Syd-1 has a RhoGAP domain, albeit one that has not been shown to interact with GTPases (Hallam et al., 2002). Syd-1 may act distantly upstream of Trio. However, it is also possible that Syd-1 might instead regulate one or more small GTPases in parallel with Trio. GAPs and GEFs have opposite effects on GTPases, but loss of trio or syd-1 causes similar defects at both NMJ and in R7s. One possibility, therefore, is that Syd-1 acts as a GAP not for Racl but for Rho, which often functions in opposition to Rac (Guilluy et al., 2011). Alternatively, Syd-1 might act as an atypical GAP for Racl-perhaps lacking GAP activity but able to bind and protect Rac1-GTP from conventional GAPs_ - or Syd-1 might yet act as a conventional GAP for Rac1 if it is the rate of cycling between GDP- and GTP-bound states of Racl (rather than simply the amount of the GTPase that is in the "active," GTP-bound, state) that promotes presynaptic development.

\section{References}

Ashley JA, Katz FN (1994) Competition and position-dependent targeting in the development of the Drosophila R7 visual projections. Development 120:1537-1547. Medline

Astigarraga S, Hofmeyer K, Farajian R, Treisman JE (2010) Three Drosophila Liprins interact to control synapse formation. J Neurosci 30:1535815368. CrossRef Medline

Ball RW, Warren-Paquin M, Tsurudome K, Liao EH, Elazzouzi F, Cavanagh C, An BS, Wang TT, White JH, Haghighi AP (2010) Retrograde BMP signaling controls synaptic growth at the NMJ by regulating Trio expression in motor neurons. Neuron 66:536-549. CrossRef Medline

Barkus RV, Klyachko O, Horiuchi D, Dickson BJ, Saxton WM (2008) Identification of an axonal Kinesin-3 motor for fast anterograde vesicle transport that facilitates retrograde transport of neuropeptides. Mol Biol Cell 19:274-283. CrossRef Medline

Berger J, Suzuki T, Senti KA, Stubbs J, Schaffner G, Dickson BJ (2001) Genetic mapping with SNP markers in Drosophila. Nat Genet 29:475-481. CrossRef Medline

Bloomquist BT, Shortridge RD, Schneuwly S, Perdew M, Montell C, Steller H, Rubin G, Pak WL (1988) Isolation of a putative phospholipase C gene of Drosophila, norpA, and its role in phototransduction. Cell 54:723-733. CrossRef Medline

Choe KM, Prakash S, Bright A, Clandinin TR (2006) Liprin- $\alpha$ is required for photoreceptor target selection in Drosophila. Proc Natl Acad Sci U S A 103:11601-11606. CrossRef Medline

Clandinin TR, Lee CH, Herman T, Lee RC, Yang AY, Ovasapyan S, Zipursky SL (2001) Drosophila LAR regulates R1-R6 and R7 target specificity in the visual system. Neuron 32:237-248. CrossRef Medline

Dai Y, Taru H, Deken SL, Grill B, Ackley B, Nonet ML, Jin Y (2006) SYD-2 Liprin- $\alpha$ organizes presynaptic active zone formation through ELKS. Nat Neurosci 9:1479-1487. CrossRef Medline

Gao S, Takemura SY, Ting CY, Huang S, Lu Z, Luan H, Rister J, Thum AS, Yang M, Hong ST, Wang JW, Odenwald WF, White BH, Meinertzhagen IA, Lee CH (2008) The neural substrate of spectral preference in Drosophila. Neuron 60:328-342. CrossRef Medline

Guilluy C, Garcia-Mata R, Burridge K (2011) Rho protein crosstalk: another social network? Trends Cell Biol 21:718-726. CrossRef Medline

Guo X, Macleod GT, Wellington A, Hu F, Panchumarthi S, Schoenfield M, Marin L, Charlton MP, Atwood HL, Zinsmaier KE (2005) The GTPase dMiro is required for axonal transport of mitochondria to Drosophila synapses. Neuron 47:379-393. CrossRef Medline

Hallam SJ, Goncharov A, McEwen J, Baran R, Jin Y (2002) SYD-1, a presynaptic protein with PDZ, C2, and RhoGAP-like domains, specifies axon identity in C. elegans. Nat Neurosci 5:1137-1146. CrossRef Medline

Hofmeyer K, Treisman JE (2009) The receptor protein tyrosine phosphatase LAR promotes R7 photoreceptor axon targeting by a phosphataseindependent signaling mechanism. Proc Natl Acad Sci U S A 106:19399_ 19404. CrossRef Medline

Hofmeyer K, Maurel-Zaffran C, Sink H, Treisman JE (2006) Liprin- $\alpha$ has LAR-independent functions in R7 photoreceptor axon targeting. Proc Natl Acad Sci U S A 103:11595-11600. CrossRef Medline

Kaufmann N, DeProto J, Ranjan R, Wan H, Van Vactor D (2002) Drosophila Liprin- $\alpha$ and the receptor phosphatase Dlar control synapse morphogenesis. Neuron 34:27-38. CrossRef Medline

Lee CH, Herman T, Clandinin TR, Lee R, Zipursky SL (2001) N-cadherin regulates target specificity in the Drosophila visual system. Neuron 30: 437-450. CrossRef Medline

Lee T, Luo L (1999) Mosaic analysis with a repressible cell marker for studies of gene function in neuronal morphogenesis. Neuron 22:451-461. CrossRef Medline

Louie K, Russo GJ, Salkoff DB, Wellington A, Zinsmaier KE (2008) Effects of imaging conditions on mitochondrial transport and length in larval motor axons of Drosophila. Comp Biochem Physiol A Mol Integr Physiol 151:159-172. CrossRef Medline

Mahr A, Aberle H (2006) The expression pattern of the Drosophila vesicular glutamate transporter. Gene Expression Patterns 6:299-309. CrossRef Medline 
Maurel-Zaffran C, Suzuki T, Gahmon G, Treisman JE, Dickson BJ (2001) Cell-autonomous and -nonautonomous functions of LAR in R7 photoreceptor axon targeting. Neuron 32:225-235. CrossRef Medline

McKay RR, Chen DM, Miller K, Kim S, Stark WS, Shortridge RD (1995) Phospholipase C rescues visual defect in norpA mutant of Drosophila melanogaster. J Biol Chem 270:13271-13276. CrossRef Medline

Miller AC, Seymour H, King C, Herman TG (2008) Loss of seven-up from Drosophila R1/R6 photoreceptors reveals a stochastic fate choice that is normally biased by Notch. Development 135:707-715. CrossRef Medline

Miller KE, DeProto J, Kaufmann N, Patel BN, Duckworth A, Van Vactor D (2005) Direct observation demonstrates that Liprin- $\alpha$ is required for trafficking of synaptic vesicles. Curr Biol 15:684-689. CrossRef Medline

Morante J, Desplan C (2008) The color-vision circuit in the medulla of Drosophila. Curr Biol 18:553-565. CrossRef Medline

Morey M, Yee SK, Herman T, Nern A, Blanco E, Zipursky SL (2008) Coordinate control of synaptic layer specificity and rhodopsins in photoreceptor neurons. Nature 456:795-799. CrossRef Medline

Moua P, Fullerton D, Serbus LR, Warrior R, Saxton WM (2011) Kinesin-1 tail autoregulation and microtubule-binding regions function in saltatory transport but not ooplasmic streaming. Development 138:1087-1092. CrossRef Medline

Mullins MC, Rubin GM (1991) Isolation of temperature-sensitive mutations of the tyrosine kinase receptor sevenless (sev) in Drosophila and their use in determining its time of action. Proc Natl Acad Sci U S A 88:93879391. CrossRef

Nern A, Nguyen LV, Herman T, Prakash S, Clandinin TR, Zipursky SL (2005) An isoform-specific allele of Drosophila N-cadherin disrupts a late step of R7 targeting. Proc Natl Acad Sci U S A 102:12944-12949. CrossRef Medline

Newsome TP, Schmidt S, Dietzl G, Keleman K, Asling B, Debant A, Dickson BJ (2000) Trio combines with Dock to regulate Pak activity during photoreceptor axon pathfinding in Drosophila. Cell 101:283-294. CrossRef Medline

Owald D, Fouquet W, Schmidt M, Wichmann C, Mertel S, Depner H, Christiansen F, Zube C, Quentin C, Korner J, Urlaub H, Mechtler K, Sigrist S (2010) A Syd-1 homologue regulates pre- and postsynaptic maturation in Drosophila. J Cell Biol 188:563-579. CrossRef

Owald D, Khorramshahi O, Gupta VK, Banovic D, Depner H, Fouquet W, Wichmann C, Mertel S, Eimer S, Reynolds E, Holt M, Aberle H, Sigrist SJ (2012) Cooperation of Syd-1 with Neurexin synchronizes pre- with postsynaptic assembly. Nat Neurosci 15:1219-1226. CrossRef Medline

Pack-Chung E, Kurshan PT, Dickman DK, Schwarz TL (2007) A Drosophila Kinesin required for synaptic bouton formation and synaptic vesicle transport. Nat Neurosci 10:980-989. CrossRef Medline

Parks AL, Cook KR, Belvin M, Dompe NA, Fawcett R, Huppert K, Tan LR, Winter CG, Bogart KP, Deal JE, Deal-Herr ME, Grant D, Marcinko M, Miyazaki WY, Robertson S, Shaw KJ, Tabios M, Vysotskaia V, Zhao L, Andrade RS, et al. (2004) Systematic generation of high-resolution deletion coverage of the Drosophila melanogaster genome. Nat Genet 36: 288-292. CrossRef Medline

Patel MR, Shen K (2009) RSY-1 is a local inhibitor of presynaptic assembly in C. elegans. Science 323:1500-1503. CrossRef Medline

Patel MR, Lehrman EK, Poon VY, Crump JG, Zhen M, Bargmann CI, Shen K (2006) Hierarchical assembly of presynaptic components in defined $C$. elegans synapses. Nat Neurosci 9:1488-1498. CrossRef Medline

Pearn MT, Randall LL, Shortridge RD, Burg MG, Pak WL (1996) Molecular, biochemical, and electrophysiological characterization of Drosophila norpA mutants. J Biol Chem 271:4937-4945. CrossRef Medline
Rao S, Lang C, Levitan ES, Deitcher DL (2001) Visualization of neuropeptide expression, transport, and exocytosis in Drosophila melanogaster. J Neurobiol 49:159-172. CrossRef Medline

Riesgo-Escovar J, Raha D, Carlson JR (1995) Requirement for a phospholipase C in odor response: Overlap between olfaction and vision in Drosophila. Proc Natl Acad Sci U S A 92:2864-2868. CrossRef Medline

Schindelin J, Arganda-Carreras I, Frise E, Kaynig V, Longair M, Pietzsch T, Preibisch S, Rueden C, Saalfeld S, Schmid B, Tinevez JY, White DJ, Hartenstein V, Eliceiri K, Tomancak P, Cardona A (2012) Fiji: an opensource platform for biological-image analysis. Nat Methods 9:676-682. CrossRef Medline

Sellers VM, Wang KF, Johnson MK, Dailey HA (1998) Evidence that the fourth ligand to the $[2 \mathrm{Fe}-2 \mathrm{~S}]$ cluster in animal ferrochelatase is a cysteine. Characterization of the enzyme from Drosophila melanogaster. J Biol Chem 273:22311-22316. CrossRef Medline

Shin H, Wyszynski M, Huh KH, Valtschanoff JG, Lee JR, Ko J, Streuli M, Weinberg RJ, Sheng M, Kim E (2003) Association of the Kinesin motor KIF1A with the multimodular protein Liprin- $\alpha$. J Biol Chem 278:11393-11401. CrossRef Medline

Stowers RS, Schwarz TL (1999) A genetic method for generating Drosophila eyes composed exclusively of mitotic clones of a single genotype. Genetics 152:1631-1639. Medline

Stryker E, Johnson KG (2007) LAR, liprin $\alpha$ and the regulation of active zone morphogenesis. J Cell Sci 120:3723-3728. CrossRef Medline

Stuart AE, Borycz J, Meinertzhagen IA (2007) The dynamics of signaling at the histaminergic photoreceptor synapse of arthropods. Prog Neurobiol 82:202-227. CrossRef Medline

Takemura SY, Lu Z, Meinertzhagen IA (2008) Synaptic circuits of the Drosophila optic lobe: the input terminals to the medulla. J Comp Neurol 509:493-513. CrossRef Medline

Taru H, Jin Y (2011) The Liprin homology domain is essential for the homomeric interaction of SYD-2/Liprin- $\alpha$ protein in presynaptic assembly. J Neurosci 31:16261-16268. CrossRef Medline

Ting CY, Yonekura S, Chung P, Hsu SN, Robertson HM, Chiba A, Lee CH (2005) Drosophila N-cadherin functions in the first stage of the two-stage layer-selection process of R7 photoreceptor afferents. Development 132: 953-963. CrossRef Medline

Ting CY, Herman T, Yonekura S, Gao S, Wang J, Serpe M, O'Connor MB, Zipursky SL, Lee CH (2007) Tiling of R7 axons in the Drosophila visual system is mediated both by transduction of an Activin signal to the nucleus and by mutual repulsion. Neuron 56:793-806. CrossRef Medline

Wagner OI, Esposito A, Köhler B, Chen CW, Shen CP, Wu GH, Butkevich E, Mandalapu S, Wenzel D, Wouters FS, Klopfenstein DR (2009) Synaptic scaffolding protein SYD-2 clusters and activates kinesin-3 UNC-104 in C. elegans. Proc Natl Acad Sci U S A 106:19605-19610. CrossRef Medline

Wernet MF, Mazzoni EO, Celik A, Duncan DM, Duncan I, Desplan C (2006) Stochastic Spineless expression creates the retinal mosaic for colour vision. Nature 440:174-180. CrossRef Medline

Yeh E, Gustafson K, Boulianne GL (1995) Green fluorescent protein as a vital marker and reporter of gene expression in Drosophila. Proc Natl Acad Sci U S A 92:7036-7040. CrossRef Medline

Zhang YQ, Rodesch CK, Broadie K (2002) Living synaptic vesicle marker: synaptotagmin-GFP. Genesis 34:142-145. CrossRef Medline

Zhen M, Jin Y (1999) The liprin protein SYD-2 regulates the differentiation of presynaptic termini in C. elegans. Nature 401:371-375. CrossRef Medline 